\title{
In Silico Investigations on Curcuminoids from Curcuma longa as Positive Regulators of Wnt/ß-catenin Signaling Pathway in Wound Healing
}

Riyan Al Islam Reshad ${ }^{1}$, Sayka Alam ${ }^{2}$, Humaira Binte Raihan ${ }^{3}$, Kamrun Nahar Meem ${ }^{4}$, Fatima Rahman $^{1}$, Fardin Zahid ${ }^{1}$, Md. Ikram Rafid ${ }^{1}$, S.M. Obaydur Rahman ${ }^{5}$, Sadman Omit ${ }^{6}$, Md. Hazrat $\mathrm{Ali}^{*}$

${ }^{1}$ Department of Genetic Engineering and Biotechnology, Shahjalal University of Science and Technology, Sylhet, Bangladesh

${ }^{2}$ Department of Biotechnology and Genetic Engineering, Jahangirnagar University, Dhaka, Bangladesh

${ }^{3}$ Department of Biochemistry and Microbiology, North South University, Bashundhara, Dhaka, Bangladesh

${ }^{4}$ Department of Genetic Engineering and Biotechnology, University of Chittagong, Chittagong, Bangladesh

${ }^{5}$ Department of Computer Science and Engineering, Shahjalal University of Science and Technology, Sylhet, Bangladesh

${ }^{6}$ Department of Biotechnology and Genetic Engineering, Sylhet Agricultural University, Sylhet, Bangladesh 


\begin{abstract}
Curcuma longa (Turmeric) is a traditionally used herb in wound healing. The efficacy of fresh Turmeric paste to heal wound has already been investigated in multiple ethnobotanical studies. Wnt/ $\beta$-catenin signaling pathway plays a significant role in wound healing and injury repair processes which has been evident in different in vitro studies. This study aims to analyze the potentiality of Curcuminoids (Curcumin I, Curcumin II and Curcumin III) from Curcuma longa to bind and enhance the activity of two intracellular signaling proteins- Casein Kinase-1 (CK1) and Glycogen Synthase Kinase-3 $\beta$ (GSK3B) involved in Wnt/ $\beta$-catenin signaling pathway. Present study is largely based on computer-based molecular docking program which mimics the in vivo condition and works on specific algorithm to interpret the binding affinity and poses of a ligand molecule to a receptor. Curcumin I showed better affinity of binding with CK1 (-10.31 Kcal/mol binding energy) and Curcumin II showed better binding affinity $(-7.55 \mathrm{Kcal} / \mathrm{mol}$ binding energy) for GSK3B. Subsequently, Drug likeness property, ADME/Toxicity profile, Pharmacological activity and Site of metabolism of the Curcuminoids were also analyzed. All of the ligand molecules showed quite similar pharmacological properties.
\end{abstract}

\title{
1. Introduction
}

\subsection{Wound, Wound Healing Process and Treatments}

Skin is the largest organ of the body which act as a primary protective barrier. Any physical damage on the skin, causes exposure of subcutaneous tissue following a loss of skin integrity known as wound. Wound provides a moist, warm, and nutritious environment that is suitable for microbial colonization and proliferation [1]. Infected wounds harbor diverse populations of microorganisms. However, in some cases these microorganisms can be difficult to identify and 
fail to respond to antibiotic treatment, resulting in chronic non-healing wounds due to the formation biofilm [2].

Wound healing takes place by three main events: Inflammatory phase, Proliferative phase and Maturation and remodeling phage. During the inflammatory phase there is an influx of inflammatory cells and local Wnt/ $\beta$-catenin signaling begins to increase [3]. Wnt proteins are glycoproteins that regulate cell proliferation, migration and specification of cell fate. Wnt proteins are classified according to their ability to promote stabilization of $\beta$-catenin in the cytoplasm. The $\beta$-catenin-dependent Wnt pathway signals through cytoplasmic stabilization and accumulation of $\beta$-catenin in the nucleus to activate gene transcription which leads to cell division and cell proliferation [4]. During the proliferative phase a scab (eschar) is formed and the wound is reepithelialized. This phase includes an increased local Wnt response, which increases the accumulation of $\beta$-catenin in the cytoplasm. Increases in $\beta$-catenin level leads to some gene transcriptions, such as the matrix metalloproteinases, which causes extracellular matrix deposition, angiogenesis, and the recruitment and proliferation of multiple cell types including stem cells, keratinocytes, and fibroblasts. The third phase, the maturation and remodeling phase, is characterized by extensive extracellular matrix remodeling [3][5].

Lots of treatments for wound care are available in the market. One of most commonly used is Standard wound healing technique and wound dressing. A wound dressing includes a cover membrane comprising a semi-permeable material with an adhesive-coated skin contact surface. An intermediate layer of material may be placed between the wound and the membrane contact surface for either absorbing fluids from the wound, e.g. with a hydrocolloid or hydrophilic material, or for passing such fluids to the opening with a synthetic material, e.g. rayon [6]. On other hand standard wound technique includes wet-to-dry dressings, gel and sliver sulfadiazine 
(Slivadene). Another method is Vacuum Assisted Closure (VAC) therapy, which is most effective than standard wound healing. This therapy accelerates the healing process by removal of edema and stimulation of mitosis through cell deformation. Success of the treatment depends on the condition of the wound [7]. 1\% silver sulfadiazine, an antimicrobial topical ointment, is one the popular medicine in treatment of burn wounds around the world. It is easy and convenient to use, causes no pain, low toxicity and sensitivity. However, studies have shown that this drug also causes side effects such as reduction of white blood cells, toxic epidermal necrolysis, increased skin pigmentation, neutropenia, increased bacterial resistance and the skin appearance would not return to normal. For some countries, like Iran raw materials are often needed to be imported at higher prices [8]. Moreover, an estimated US\$ 25 billion is spent annually only in USA for the wound healing purposes and the margin is increasing day by day due to the increasing healthcare cost. While current therapeutic agents have lower efficacy and many adverse side effects, medicinal plants which are being used as medicine from very ancient time have been proven effective and safe for wound healing and thus herbal medicine can be a lucrative alternative of current therapeutic agents [9]. Turmeric is extensively used as spice, preservatives and coloring material in food. Numerous studies have been conducted with Turmeric over the last few decades which have proven its multiple functions in combating multiple diseases. It contains Sabinene, Borneol, Zingiberene and some other major phytochemicals of great therapeutic values as well as Curcuminoid which are responsible for the yellow color of Turmeric and it comprises Curcumin I, II and III [10] [11]. Role of both Turmeric and individual Curcumin from the plant in wound healing has already been demonstrated in laboratory experiments [10][12]. 


\subsection{Wnt/ß-catenin Pathway and Its Involvement in Wound Healing}

The Wnt/ $\beta$-catenin signaling pathway is activated by the binding of secreted Wnt proteins to a receptor complex containing a member of the FZD family and LRP5/6 [13]. A number of complex proteins facilitate the Wnt/ $\beta$-catenin Pathway. Casein Kinase-1 (CK1) and Glycogen Synthase Kinase-3 $\beta$ (GSK3B) phosphorylate several important components like B-catenin, Axin and APC (Adenomatous Polyposis Coli), in the Wnt/ $\beta$-catenin signaling pathway and act as either negative or positive regulators of the pathway. These phosphorylation events result in tighter association of Axin and APC with b-catenin CK1 is a family of serine/threonine-specific protein kinases regulates diverse cellular processes like Wnt signaling [14]. They phosphorylate several pathway components and exert a dual function, acting as both Wnt activators and Wnt inhibitors. The CK1 family consists of six human isoforms $(\alpha, \delta, \varepsilon, \gamma 1, \gamma 2, \gamma 3)$ are ubiquitously expressed and share a highly homologous kinase domain, flanked by variable Nterminal and C-terminal extensions. The amino-terminal kinase domain is highly conserved in all CK1 family members [13] [15]. The serine/threonine kinase GSK3B binds to and phosphorylates several proteins in the Wnt pathway and is serving to the down regulation of $\beta$-catenin. As a negative regulator of Wnt signaling, GSK3B would qualify as a potential tumor suppressor [16].

\subsubsection{Wnt/ß-catenin Pathway in Absence of Wnt Ligand}

In absence of Wnt ligand, $\beta$-catenin is phosphorylated and targeted to degradation by a protein

complex consisting of several molecules including Axin, APC, CK1, and GSK3B. Axin is a protein which serves as a scaffold for formation of destruction complex (Figure 1) [17]. APC is a large protein that interacts with both $\beta$-catenin and Axin. It contains three Axin-binding motifs that are interspersed between a series of 15 and 20 amino acid repeats[18].The scaffolding protein Axin and tumor suppressor APC form a $\beta$-catenin destruction complex that binds 
cytosolic $\beta$-catenin and sequentially phosphorylate specific $\mathrm{N}$-terminal residues of $\beta$-catenin by serine/threonine kinases, casein kinase $1 \gamma(\mathrm{CK} 1 \gamma)$ and glycogen synthase kinase $3 \beta$ (GSK3B) [19] [20]. Once $\beta$-catenin is hold into the destruction complex by APC and phosphorylated by GSK3B, the phosphorylated $\beta$-catenin is a target for $\beta$-Trcp which is E3-ubiquitin ligase. $\beta$-Trcp transfers ubiquitin chain to the $\beta$-catenin and ubiquitinated $\beta$-catenin degrades via ubiquitin proteasome mediated pathway [18] [21]. In the nucleus, the Wnt target genes are bound by transcription factors of TCF/ LEF. In absence of $\beta$-catenin these TCF/LEF transcription factors are bound to Groucho which is a transcriptional repressor, does not allow the Wnt target genes to express [22][23].

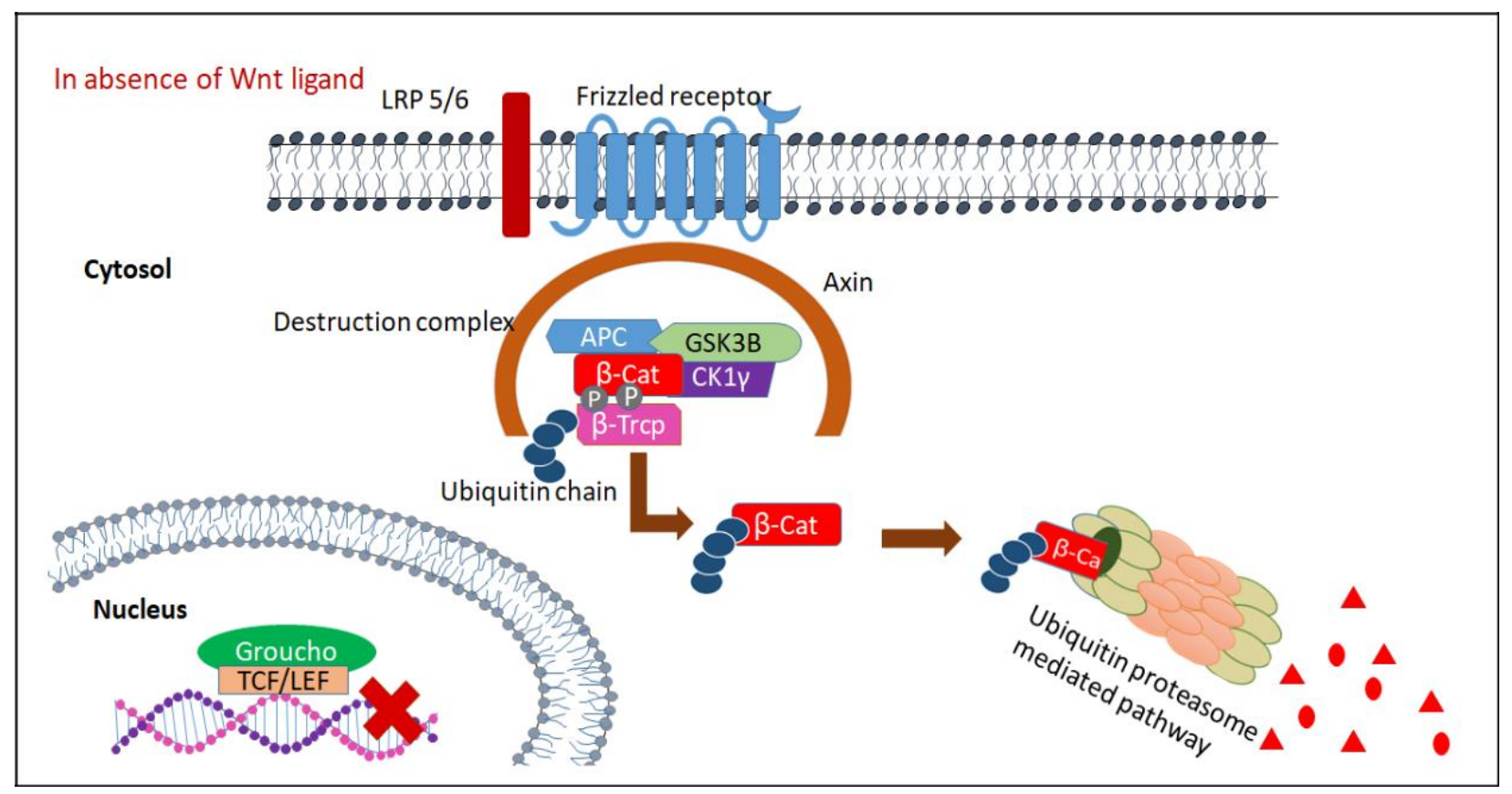

Figure 1: In the absence of Wnt proteins, Axin, APC, $\beta$-catenin, and GSK3B form a complex, in which $\beta$-catenin is phosphorylated by CK1 and GSK3B, leading to $\beta$-catenin degradation via Ubiquitin proteasome mediated pathway. 


\subsubsection{Wnt//-catenin Pathway in Presence of Wnt Ligand}

In presence of Wnt ligand, The Wnt signaling cascade is triggered upon binding of members of the Wnt family proteins to a co-receptor complex, including frizzled (Fz, a $\mathrm{G}$ protein-coupled receptor-like protein) and LRP5 or -6 (Figure 2). The signal is transmitted through recruitment of several proteins to the C-terminal intracellular moieties of the activated Fz and LRP5/6 coreceptors. From this point, binding Wnt ligand to the frizzled receptor leads to dimerization of LRP 5/6 with frizzled receptor. Dishevelled (DVL), a cytoplasmic binding protein which binds to the frizzled receptor, leads to instability of destruction complex [24]. Disheveled (Dvl) is recruited and posttranslationally modified, and depending on the specific nature of the Wnt and of the Fz that are complexed with LRP5/6, three independent pathways can be activated: canonical, noncanonical, or $\mathrm{Ca} 2$ [25].This instable destruction complex cannot hold $\beta$-catenin any longer. As APC cannot hold $\beta$-catenin, $\beta$-catenin is no longer phosphorylated by GSK3B. And B-Trcp protein cannot add ubiquitin chain to $\beta$-catenin. As a result, $\beta$-catenin is degraded by Ubiquitin proteasome mediated pathway. Thus $\beta$-catenin is released to the cytosol and amount of $\beta$-catenin in the cytosol increases [23] [26]. $\beta$-catenin migrates to the nucleus and replace the Groucho repressor. The interaction of $\beta$-catenin with the $N$ terminus of Tcf converts it into an activator, translating the Wnt signal into the transient transcription of Tcf target genes [27]. $\beta$ catenin also recruits $\mathrm{CBP}$ and Brg1. These are transcriptional activator which actives the transcription of Wnt-ligand targeted genes. These Wnt-targeted genes helps in cell cycle progression from G1 phase to S phase, which leads to cell division and cell proliferation of stem cells, keratinocytes and fibroblasts. The activation of the Wnt pathway has a key role for fibroblast activation and collagen release in fibrosis. Wnt signaling stimulated the differentiation 
of resting fibroblasts into myofibroblasts, increased the release of extracellular matrix components and induced fibrosis. Stem cells, Fibroblasts and keratinocytes migrates to the wounded site as immune response. As a result, scar formation occurs at the wounded site and injury repairs [3] [21] [28].

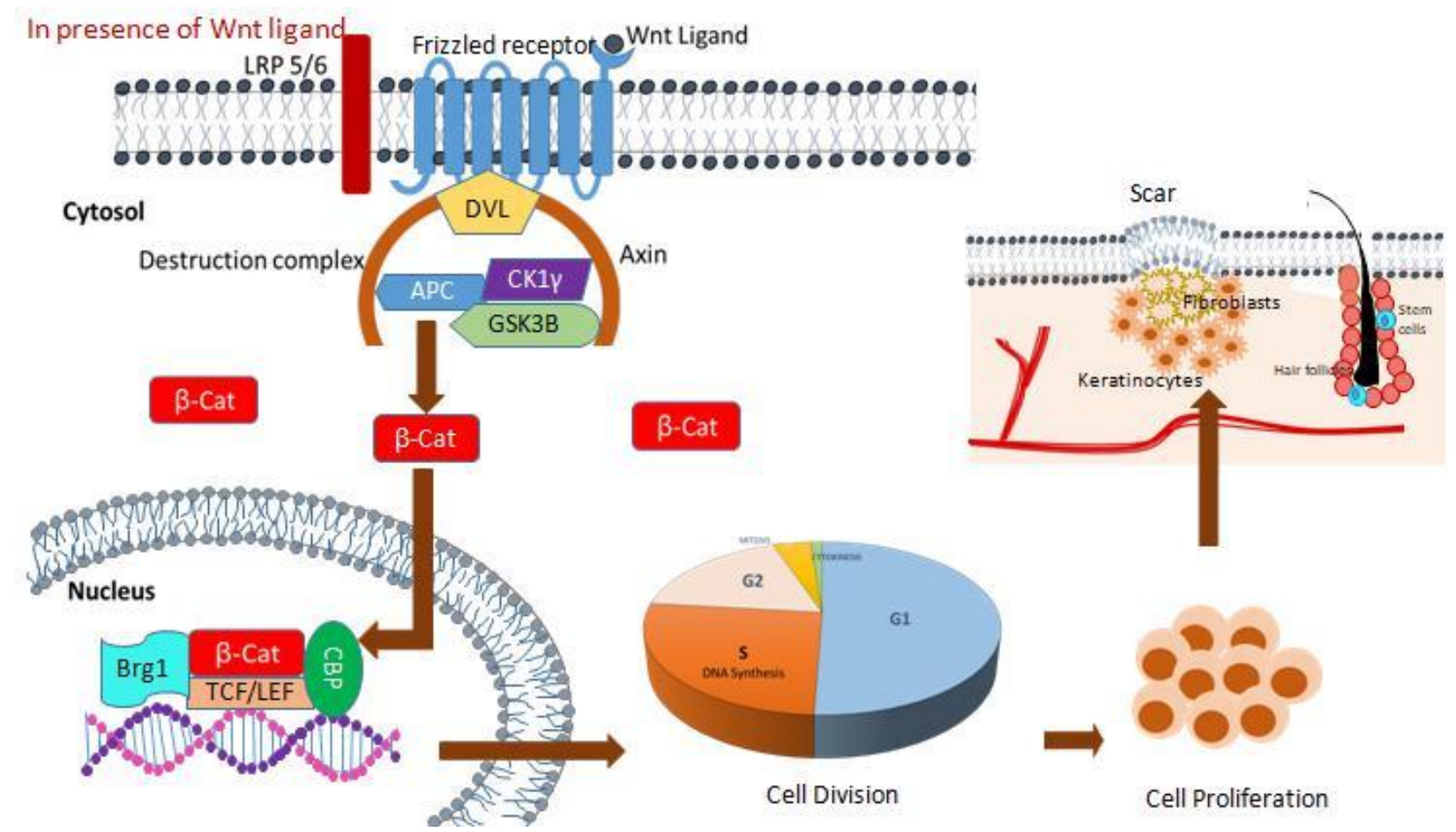

Figure 2: Wnt proteins bind to Frizzled (Fz) and LRP-5, Axin is recruited to the membranes. The interaction between Axin and LRP-5 may prevent Axin from participating in the degradation of $\beta$-catenin. Dvl may also receive signals from the Fz/LRP complex, resulting in the inhibition of GSK3B. $\beta$-catenin is not degraded, which eventually leads to transcription of the Wnt-targeted gene, which results in following event like cell division, cell proliferation and cell migration to the wound site.

In this experiment, Curcumin I, II and III (Figure 3) have been docked with two intended targets of Wnt/ $\beta$-catenin signaling pathway-CK1 and GSK3B (Figure 4) based on the hypothesis that, these phytocompounds might bind to the targets and act as a positive regulators of those targets which may lead to increased signaling and eventually effective wound healing process. Later on, 
druglikeness property, ADME/Toxicity test, Pharmacological activity and Site of metabolism of the selected phytocompounds were also analyzed.

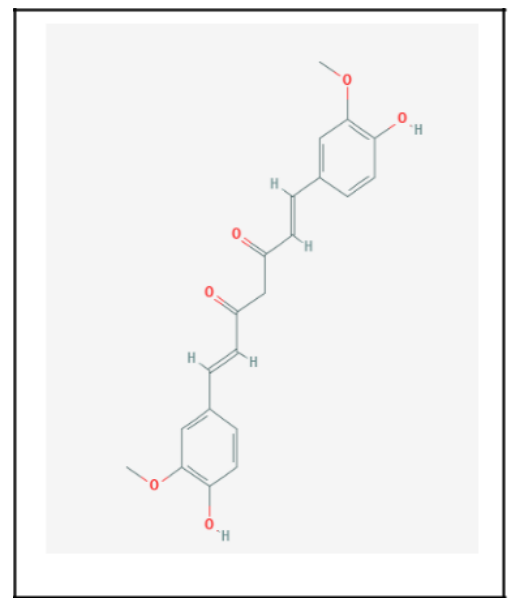

(1)

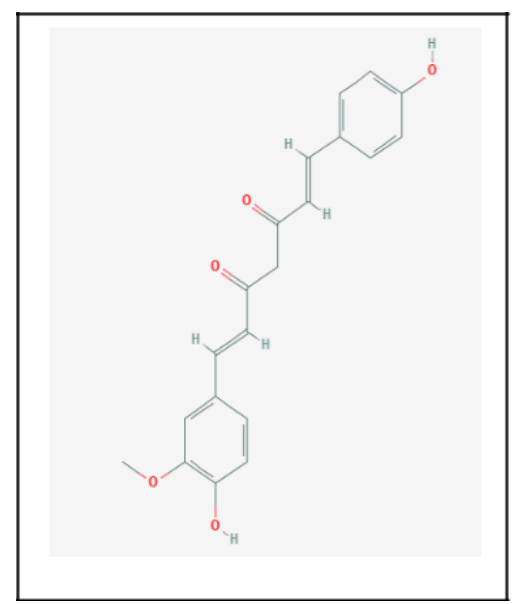

(2)
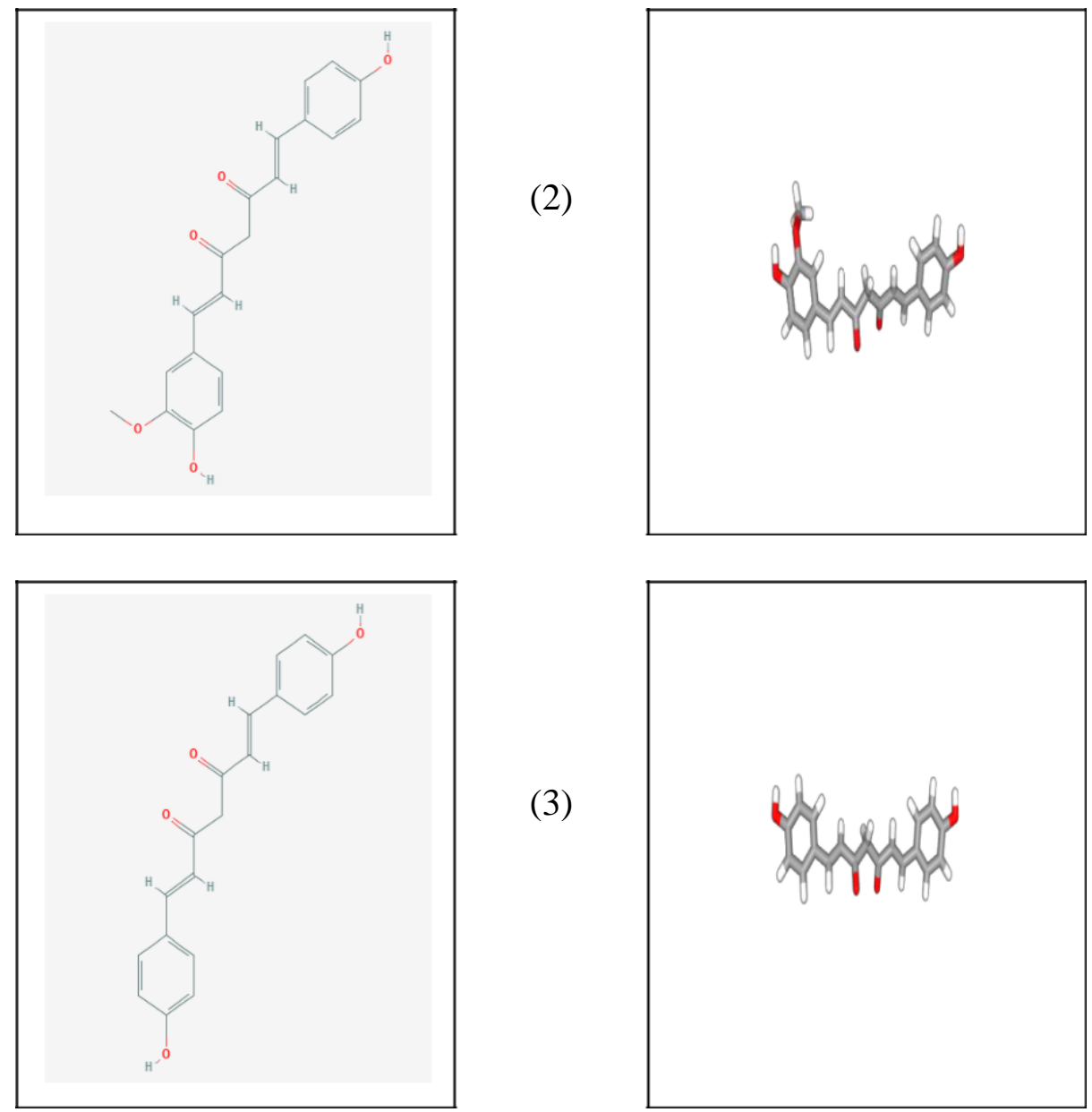

(A)

(B)

Figure 3: Structures of (1) Curcumin I (PubChem CID: 969516), (2) Curcumin II (PubChem CID: 5469424) and (3) Curcumin III (PubChem CID: 5315472); (A) 2D, (B) 3D. 


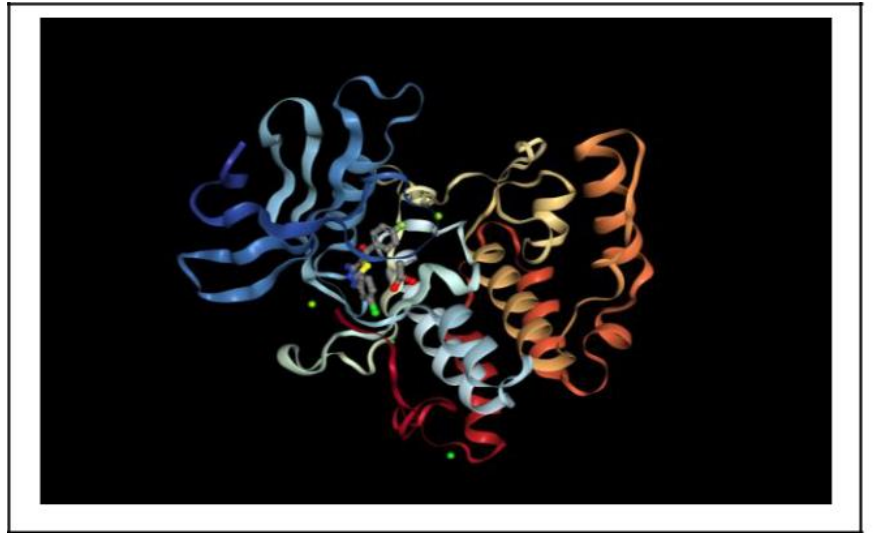

(A)

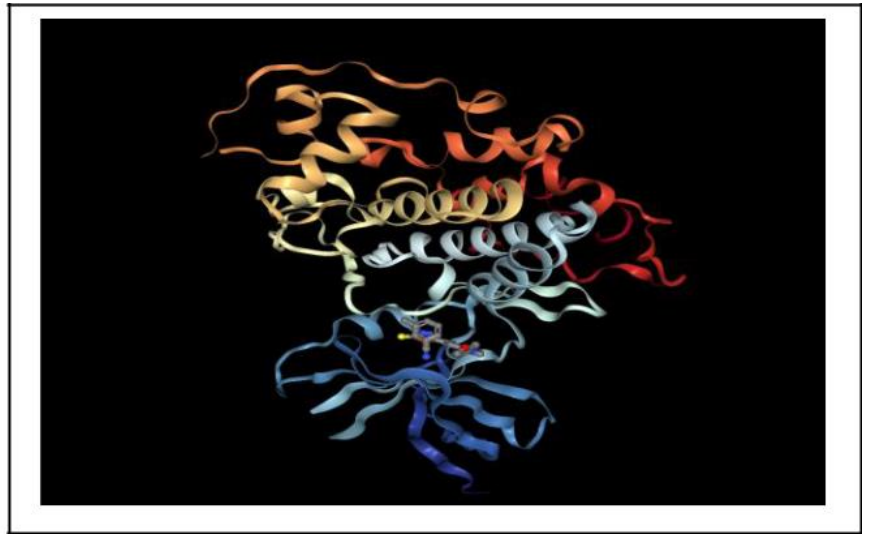

(B)

Figure 4: Three dimension structure of (A) Casein Kinase-1 (PDB Id: 2IZS), (B) Glycogen Synthase Kinase-3 $\beta$ (PDB Id: 3F88) in their native ligand bound form. Receptors are represented in cartoon style and ligands are represented in ball and stick style.

\section{Materials and Methods}

\subsection{Molecular Docking}

\subsubsection{Protein Preparation}

Three dimentional structures of Casein Kinase 1 gamma (PDB Id: 2IZS) and Glycogen Synthase Kinase-3 Beta (PDB Id: 3F88) were downloaded in PDB format from Protein Data Bank (www.rcsb.org). The structures were then prepared and processed using the Protein Preparation Wizard in Maestro Schrödinger Suite (v11.4) [29]. Bond orders were assigned to the structures, hydrogens were added to heavy atoms. All of the water molecules were erased from the atoms and selenomethionines were changed over to methionines. At last, the structures were refined and after that minimized utilizing default Optimized Potentials for Liquid Simulations force field (OPLS_2005). Minimization was performed setting the greatest substantial particle RMSD (rootmean-square-deviation) to $30 \AA$ and any extraordinary water under $3 \mathrm{H}$-bonds to non water was again eradicated during the minimization step. 


\subsubsection{Ligand Preparation}

The 3D conformations of Curcumin I (PubChem CID: 969516), Curcumin II (PubChem CID: 5469424) and Curcumin III (PubChem CID: 5315472) were downloaded from PubChem (www.pubchem.ncbi.nlm.nih.gov). These structures were then processed prepared using the LigPrep wizard of Maestro Schrödinger suite [30]. Minimized 3D structures of ligands were generated using Epik2.2 and within $\mathrm{pH} 7.0+/-2.0$ in the suite. Minimization was again carried out using OPLS_2005 force field which generated maximum 32 possible stereoisomers depending on available chiral centers on each molecule.

\subsubsection{Receptor Grid Generation}

Grid usually restricts the active site to specific area of the receptor protein for the ligand to dock specifically within that area. In Glide, a grid was generated using default Van der Waals radius scaling factor 1.0 and charge cutoff 0.25 which was then subjected to Optimized Potentials OPLS_2005 force field for the minimized structure. A cubic box was generated around the active site (reference ligand active site) of target molecules. Then the grid box dimension was adjusted to $10 \AA \times 10 \AA \times 10 \AA$ for docking to be carried out.

\subsubsection{Glide Standard Precision (SP) Ligand Docking}

SP adaptable glide docking was carried out using Glide in Maestro Schrödinger [31]. The Van der Waals radius scaling factor and charge cutoff were set to 0.80 and 0.15 respectively for all the ligand molecules under study. Final score was assigned according to the pose of docked ligand within the active site of the receptor molecules. The docking result is summarized in

Table 1. Best possible poses and types of ligand-receptor interactions (Figure 5 and 6) were analyzed utilizing Discovery Studio Visualizer [32]. 


\subsection{Structure Based Drug Likeness Property and ADME/Toxicity Prediction}

The molecular structures of every ligands were analyzed using SWISSADME server (http://www.swissadme.ch/) in order to confirm whether the physicochemical properties like molecular weight, hydrogen bond donor, hydrogen bond acceptor, molar refractivity etc. of ligands follow Lipinski's rule of five or not [33]. Additional physicochemical properties such as topological polar surface area, number of rotatable bonds, drug score, drug likeness score etc. of ligand molecules were again calculated using OSIRIS property explorer (https://www.organicchemistry.org/prog/peo/) [34]. The result of drug likeness property analysis is summarized in Table 2. ADME/T profile for each of the ligand molecules was analyzed using an online based server admetSAR (http://lmmd.ecust.edu.cn/admetsar1/predict/) to predict their various pharmacokinetic and pharmacodynamic properties including blood brain barrier permeability, human abdominal adsorption, AMES toxicity, Cytochrome P (CYP) inhibitory promiscuity, carcinogenicity, mutagenicity, Caco-2 permeability etc [35]. The result of ADME/T for all the ligand molecules is represented in Table 3.

\subsection{Structure Based Pharmacological Activity and P450 Site of Metabolism Prediction}

Biological activities of each ligand molecule were predicted using PASS (Prediction of Activity Spectra for Substances) online server (http://www.pharmaexpert.ru/passonline/) [36]. All of the ligand molecules were analyzed with respect to probability of activity (Pa) and inactivity (Pi) for 25 intended biological activities depending on their structure. Results of PASS prediction are summarized in Table 4. P450 site of metabolism of each ligand molecule was predicted using SMARTcyp online server (https://smartcyp.sund.ku.dk/mol_to_som) in order to analyze which atoms in the molecule are more prone to metabolism by Cytochrome P450 family of enzymes- 
CYP3A4, CYP2D6, CYP2C9 based on specific ligand structure [37]. Result of Cytochrome P450 site of metabolism prediction is summarized in Table 5 and Figure 7.

\section{Result}

\subsection{Molecular Docking}

All of the selected ligand molecules docked successfully with both CK1 and GSK3B with notable binding energies (Table1). Curcumin I docked with a binding energy of $-10.31 \mathrm{Kcal} / \mathrm{mol}$ within the binding site of CK1. It formed 1 conventional hydrogen bond with Glu117 with 1.62 $\AA$ distance apart and 2 conventional hydrogen bonds with Leu119 with $1.99 \AA$ and $2.44 \AA$ distance apart respectively in the binding site backbone of CK1. In addition, Curcumin I also formed two nonconventional hydrogen bonds with Lys72 and Gly140. Moreover, it interacted with 10 amino acid residues in total along with Pi-Alkyl (Hydrophobic) and Pi-Anion (Electrostatic) interactions. On the contrary, Curcumin I interacted with GSK3B with slightly lower energy $(-7.533 \mathrm{Kcal} / \mathrm{mol})$ than CK1 within the binding pocket. It formed 2 conventional hydrogen bonds with Lys85 at $2.22 \AA$ and $2.84 \AA$ distance apart and 1 conventional hydrogen bond with Val135 at $2.54 \AA$ distance apart inside the binding site of GSK3B. Curcumin I interacted with 8 amino acid residues within the binding site of GSK3B and notably with other additional types of interactions like- Pi-Sulfur, Pi-Alkyl interactions. It also formed 2 nonconventional hydrogen bonds with Pro136 and Asp200 with GSK3B.

Curcumin II docked to CK1 with a binding energy of $-7.826 \mathrm{Kcal} / \mathrm{mol}$. It formed 4 conventional hydrogen bonds- 2 with Leu119 at $1.99 \AA$ and $2.79 \AA$ distance apart and 1 with Glu117 and Asp125 each at $1.84 \AA$ and $2.09 \AA$ distance apart respectively within the binding site of CK1. Moreover, it also formed 1 nonconventional hydrogen bond with Lys72 in the binding pocket 
backbone. Curcumin II interacted with 8 amino acid residues in total with additional hydrophobic (Pi-Alkyl) binding interactions. Conversely, Curcumin II showed a subtle lower binding energy $(-7.588 \mathrm{Kcal} / \mathrm{mol})$ with GSK3B. In the binding site backbone of GSK3B it formed 2 conventional hydrogen bonds with Lys 85 at $1.87 \AA$, $2.97 \AA$ distance apart and another conventional hydrogen bond with Val135 at $2.05 \AA$ distance apart. Curcumin II also formed 2 non-conventional hydrogen bonds with Tyr134 and Asp200 within the binding site of GSK3B. With additional Pi-Alkyl, Pi-Cation and Pi-Sulfur bonding interactions Curcumin II interacted with 8 amino acid residues in total.

Curcumin III docked successfully with CK1 with $-6.356 \mathrm{Kcal} / \mathrm{mol}$ binding energy. It formed 2 conventional hydrogen bonds with Leu119 and Thr332 at $2.00 \AA$ and $2.71 \AA$ distance apart respectively within the binding pocket. It also formed 2 non-conventional hydrogen bonds with Leu118 and Pro333. Curcumin III interacted with 5 amino acids in total with one hydrophobic interaction (Pi-Alkyl) with Pro333. On the other hand, Curcumin III docked with GSK3B with slightly higher binding energy $(-6.618 \mathrm{Kcal} / \mathrm{mol})$. It formed just 1 conventional hydrogen bond with Lys60 at $1.93 \AA$ distance apart. In addition, it interacted with total 5 amino acid residues inside the binding pocket of GSK3B only with Pi-Alky hydrophobic interaction. Curcumin III didn't show any non-conventional hydrogen bonding with any amino acid residues. 


\begin{tabular}{|c|c|c|c|c|c|c|}
\hline $\begin{array}{l}\text { Compound } \\
\text { Name }\end{array}$ & Receptor & $\begin{array}{c}\text { Binding } \\
\text { Energy } \\
\text { (Kcal/mol) }\end{array}$ & $\begin{array}{c}\text { Interacting } \\
\text { Amino } \\
\text { Acids }\end{array}$ & $\begin{array}{c}\text { Bond } \\
\text { Distance } \\
(\AA)\end{array}$ & $\begin{array}{c}\text { Interaction } \\
\text { Category }\end{array}$ & $\begin{array}{c}\text { Type of } \\
\text { Interaction }\end{array}$ \\
\hline \multirow{20}{*}{ Curcumin I } & \multirow{11}{*}{ CK1 } & \multirow{11}{*}{-10.31} & Leu57 & 5.26 & Hydrophobic & Pi-Alkyl \\
\hline & & & Lys72 & 2.30 & Hydrogen bond & Non-conventional \\
\hline & & & Ala70 & 4.01 & Hydrophobic & Pi-Alkyl \\
\hline & & & Ile184 & 4.87 & Hydrophobic & Pi-Alkyl \\
\hline & & & Leu116 & 5.36 & Hydrophobic & Pi-Alkyl \\
\hline & & & Asp185 & 3.66 & Electrostatic & Pi-Anion \\
\hline & & & Glu117 & 1.62 & Hydrogen bond & Conventional \\
\hline & & & Leu119 & 1.99 & Hydrogen bond & Conventional \\
\hline & & & Gly120 & 3.01 & Hydrogen bond & Non-conventional \\
\hline & & & Leu169 & 5.36 & Hydrophobic & Pi-Alkyl \\
\hline & & & Leu119 & 2.44 & Hydrogen bond & Conventional \\
\hline & \multirow{9}{*}{ GSK3B } & \multirow{9}{*}{-7.533} & Lys85 & 2.22 & Hydrogen bond & Conventional \\
\hline & & & Lys85 & 2.84 & Hydrogen bond & Conventional \\
\hline & & & Val70 & 5.11 & Hydrophobic & Pi-Alkyl \\
\hline & & & Leu132 & 4.95 & Hydrophobic & Pi-Alkyl \\
\hline & & & Val135 & 2.54 & Hydrogen bond & Conventional \\
\hline & & & Pro136 & 2.93 & Hydrogen bond & Non-conventional \\
\hline & & & Val110 & 5.38 & Hydrophobic & Pi-Alkyl \\
\hline & & & Cys199 & 3.73 & Others & Pi-Sulfur \\
\hline & & & Asp200 & 2.56 & Hydrogen bond & Non-conventional \\
\hline \multirow{18}{*}{ Curcumin II } & \multirow{9}{*}{ CK1 } & \multirow{9}{*}{-7.826} & Glu117 & 1.84 & Hydrogen bond & Conventional \\
\hline & & & Leu119 & 1.99 & Hydrogen bond & Conventional \\
\hline & & & Leu169 & 5.25 & Hydrophobic & Pi-Alkyl \\
\hline & & & Ala70 & 4.13 & Hydrophobic & Pi-Alkyl \\
\hline & & & Asp125 & 2.09 & Hydrogen bond & Conventional \\
\hline & & & Ile184 & 4.84 & Hydrophobic & Pi-Alkyl \\
\hline & & & Lys72 & 2.54 & Hydrogen bond & Non-conventional \\
\hline & & & Leu119 & 2.79 & Hydrogen bond & Conventional \\
\hline & & & Leu57 & 5.08 & Hydrophobic & Pi-Alkyl \\
\hline & \multirow{9}{*}{ GSK3B } & \multirow{9}{*}{-7.588} & Ile62 & 4.91 & Hydrophobic & Pi-Alkyl \\
\hline & & & Val70 & 4.59 & Hydrophobic & Pi-Alkyl \\
\hline & & & Lys85 & 1.87 & Hydrogen bond & Conventional \\
\hline & & & Arg141 & 4.05 & Electrostatic & Pi-Cation \\
\hline & & & Val135 & 2.05 & Hydrogen bond & Conventional \\
\hline & & & Tyr134 & 2.39 & Hydrogen bond & Non-conventional \\
\hline & & & Lys85 & 2.97 & Hydrogen bond & Conventional \\
\hline & & & Cys199 & 3.73 & Others & Pi-Sulfur \\
\hline & & & Asp200 & 2.71 & Hydrogen bond & Non-conventional \\
\hline \multirow{9}{*}{ Curcumin III } & \multirow{4}{*}{ CK1 } & \multirow{4}{*}{-6.356} & Pro333 & 4.37 & Hydrophobic & Pi-Alkyl \\
\hline & & & Thr332 & 2.71 & Hydrogen bond & Conventional \\
\hline & & & Leu118 & 2.71 & Hydrogen bond & Non-conventional \\
\hline & & & Leu119 & 2.00 & Hydrogen bond & Conventional \\
\hline & \multirow{5}{*}{ GSK3B } & & Ile62 & 4.48 & Hydrophobic & Pi-Alkyl \\
\hline & & \multirow[t]{4}{*}{$\begin{array}{l}-6.618 \\
\end{array}$} & Val70 & 4.75 & Hydrophobic & Pi-Alkyl \\
\hline & & & Lys60 & 1.93 & Hydrogen bond & Conventional \\
\hline & & & Lys85 & 5.11 & Hydrophobic & Pi-Alkyl \\
\hline & & & Cys199 & 4.12 & Hydrophobic & Pi-Alkyl \\
\hline
\end{tabular}

Table 1: Result of molecular docking between Curcumin I (PubChem CID: 969516), Curcumin II (PubChem CID: 5469424) Curcumin, III (PubChem CID: 5315472) and CK-1 (PDB Id: 2IZS) and GSK3B (PDB Id: 3F88). 

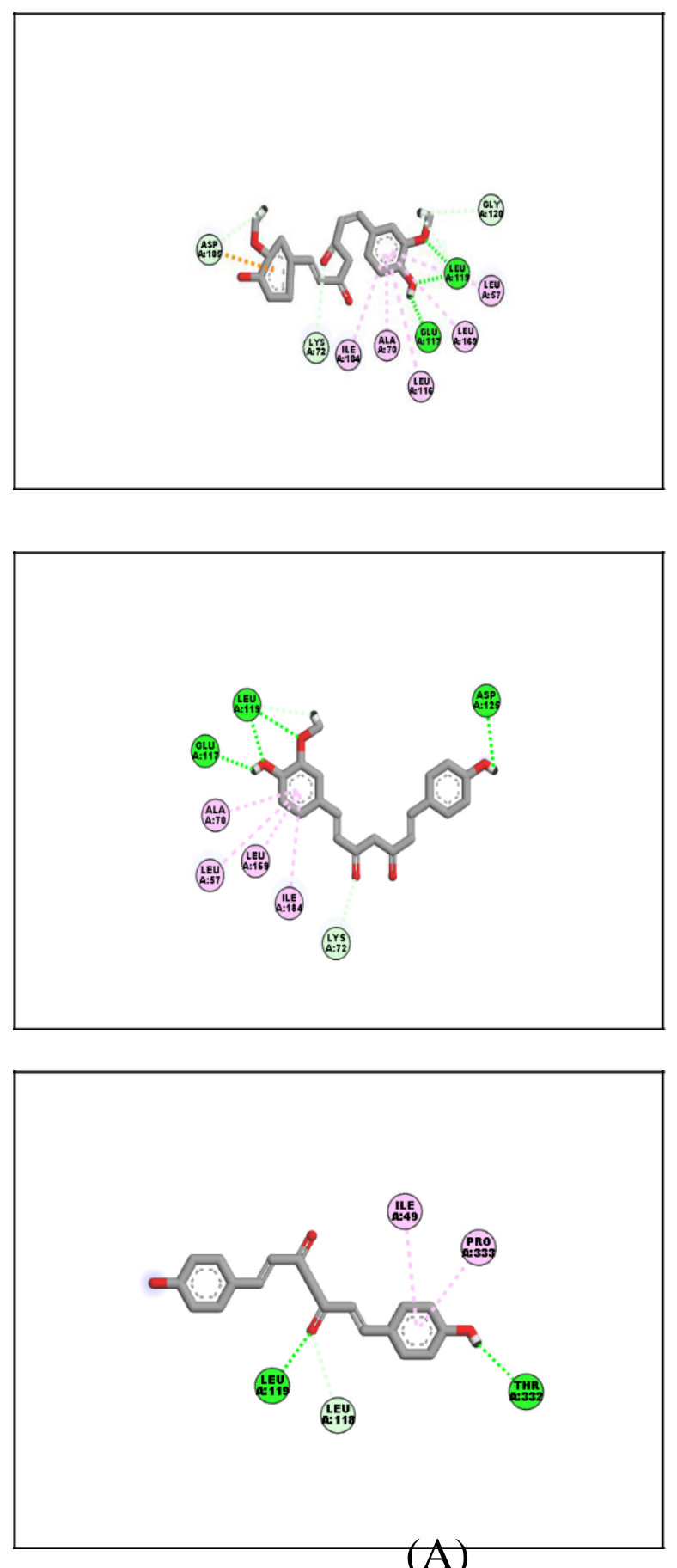

(A)
(1)

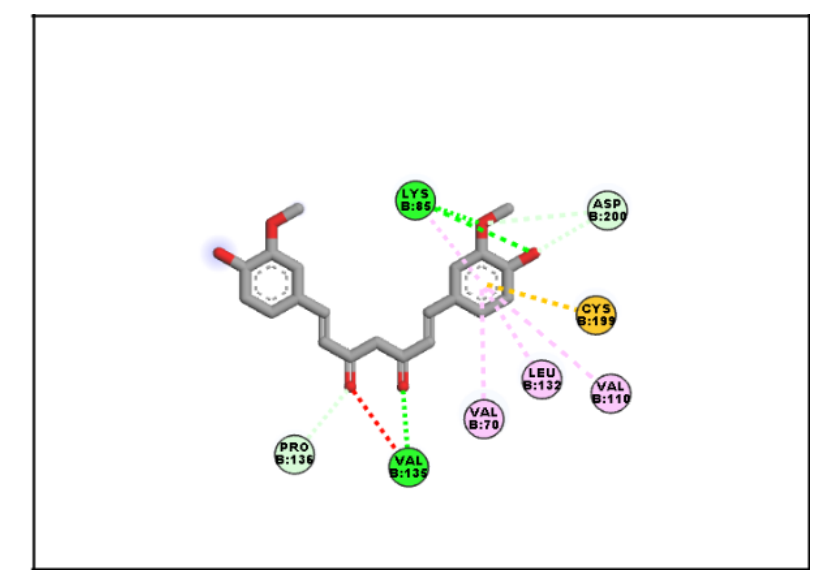

(2)

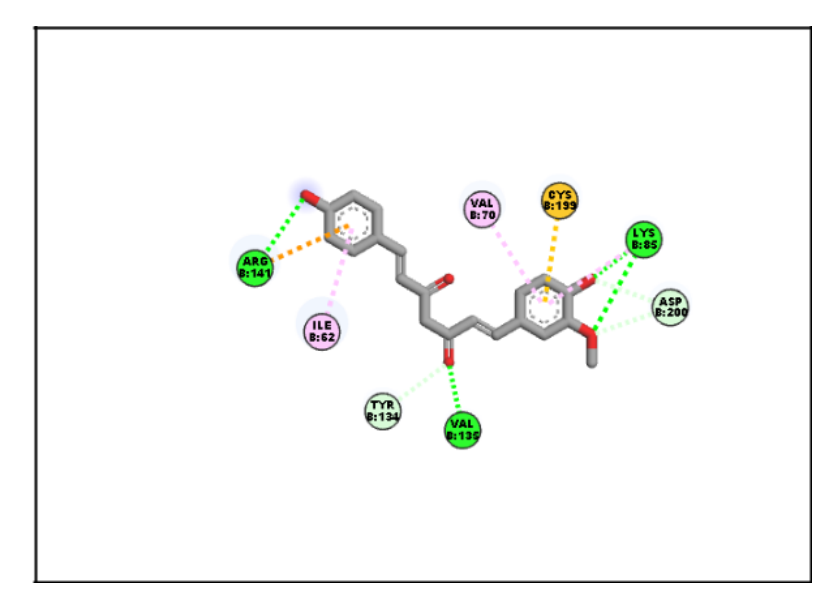

(3)

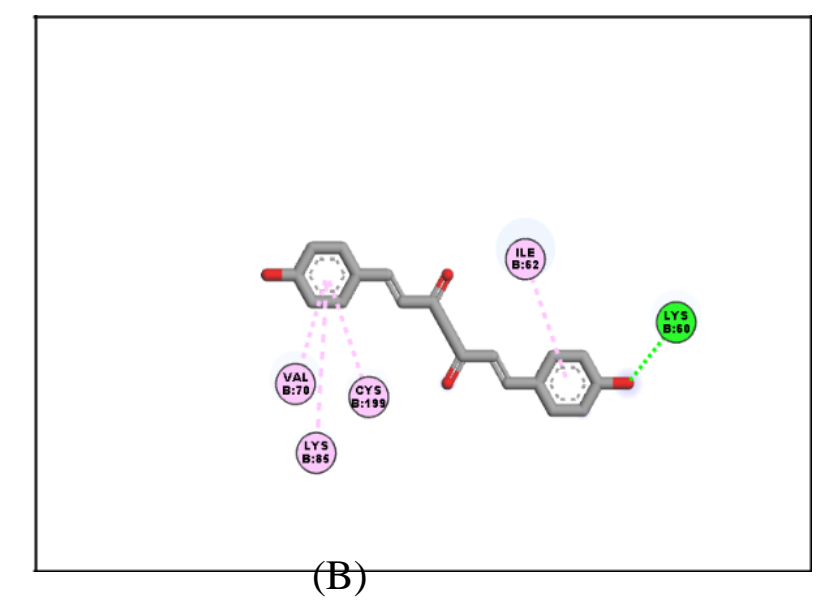

Figure 5: 2D representation of ligand-receptor interactions between (1) Curcumin I (PubChem CID: 969516), (2) Curcumin II (PubChem CID: 5469424) and (3) Curcumin III (PubChem CID: 5315472) and (A) Casein Kinase-1 (PDB Id: 2IZS), (B) Glycogen Synthase Kinase-3ß (PDB Id: 3F88). Ligand is represented as stick and interacting amino acid (labeled) of receptor is represented as disc sphere. Dotted line represents type of interactions: Dark green: Hydrogen bond; Light Green: Van Der Waals interaction; Pink: Pi-Alkyl interaction; White: Carbon hydrogen bond; Red: Acceptor-Acceptor interaction; Orange: Pi-Sulphur interaction. 


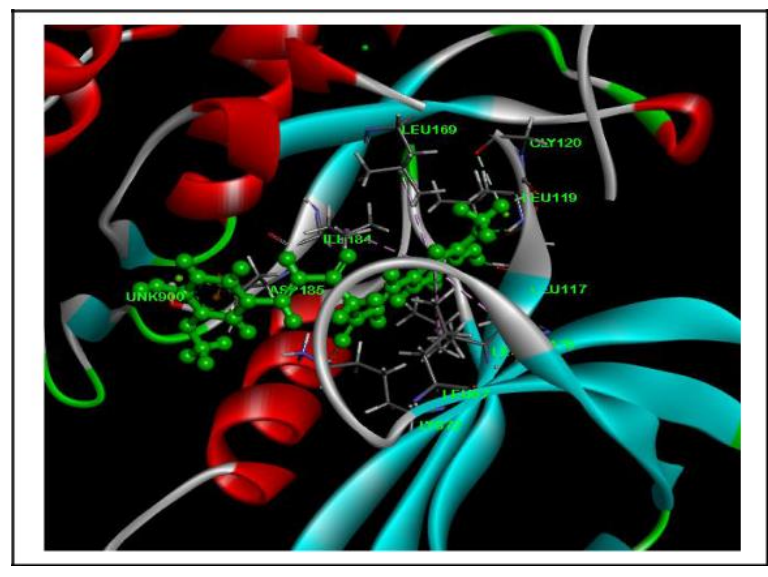

(1)
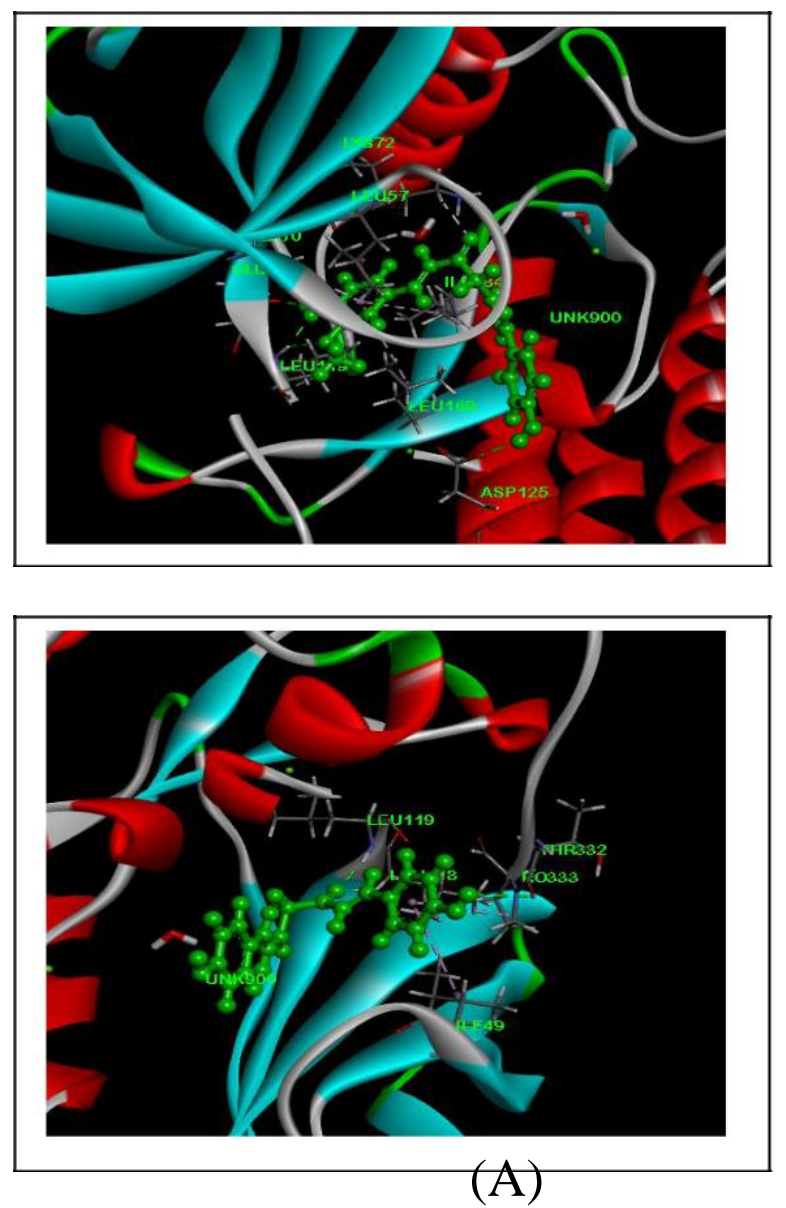

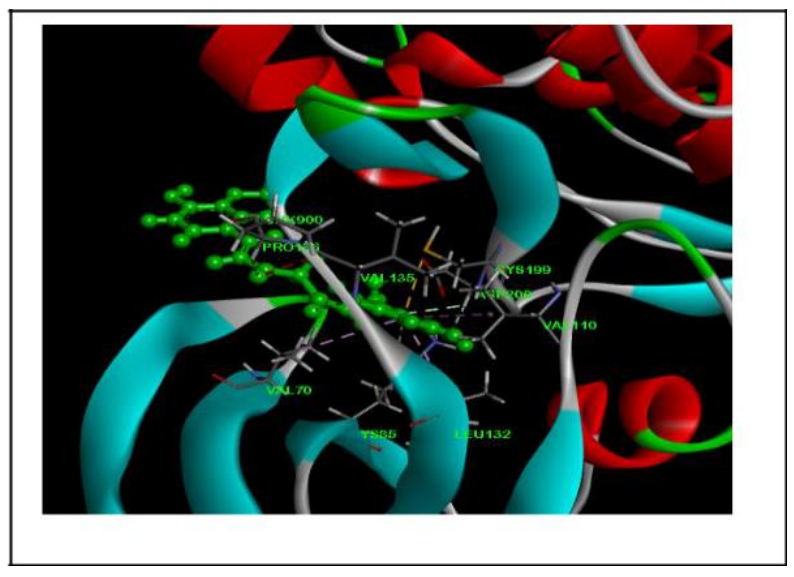

(2)

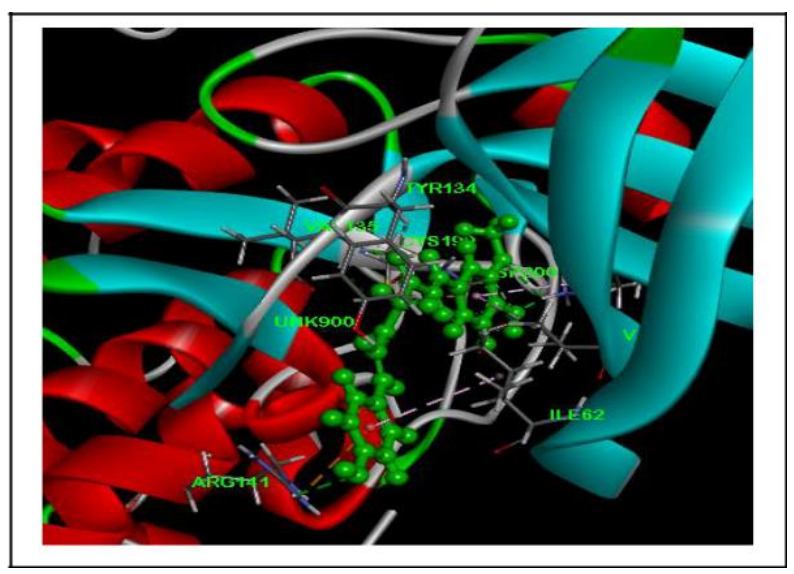

(3)

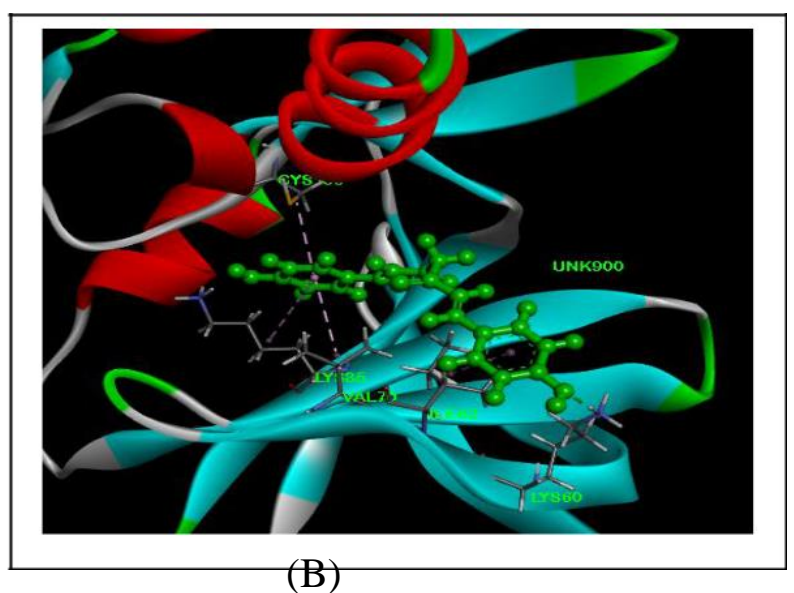

Figure 6: 3D representation of best possible poses and ligand-receptor interactions between (1) Curcumin I (PubChem CID: 969516), (2) Curcumin II (PubChem CID: 5469424) and (3) Curcumin III (PubChem CID: 5315472) and (A) Casein Kinase-1 (PDB Id: 2IZS), (B) Glycogen Synthase Kinase-3 $\beta$ (PDB Id: 3F88). Ligand (UNK: 900) is represented as ball and stick and interacting amino acid (labeled) of receptor is represented in stick style. Receptor is represented in ribbon style. Dotted line represents type of interactions: Green: Hydrogen bond; Pink: Pi-Alkyl interaction; White: Carbon hydrogen bond; Red: Acceptor-Acceptor interaction; Orange: Pi-Sulphur interaction. 


\subsection{Drug Likeness Property}

The results of drug likeness property analysis are summarized in Table 2. All of the selected ligand molecules followed Lipinski's rule of five with respect to molecular weight ( acceptable range: $<500$ ), number of hydrogen bond donors (acceptable range: $\leq 5$ ), number of hydrogen bond acceptors (acceptable range: $\leq 10$ ), lipophilicity (expressed as LogP, acceptable range: $<5$ ) and molar refractivity (40-130) [38]. Curcumin III showed lowest Topological Polar Surface Area (TPSA) of $74.60 \AA^{2}$ followed by Curcumin II (83.83 $\left.\AA^{2}\right)$ and Curcumin I (93.06 $\left.\AA^{2}\right)$. Again Curcumin III showed lowest $\operatorname{LogS}$ value (-3.80) among the three ligand molecules. Curcumin II (-3.92) and Curcumin I (-3.934) showed almost similar LogS value. Curcumin I showed the highest drug likeness score (-2.63) followed by Curcumin II (-3.55) and Curcumin III (-4.48). Curcumin II and Curcumin III showed same drug score (0.41) whereas Curcumin I showed highest drug score $(0.53)$ among the the ligand molecules. Curcumin I and II have 8 rotatable bonds and on the contrary, Curcumin III has 6 rotatable bonds. Curcumin I, II and III have 27, 12 and 23 heavy atoms respectively.

\begin{tabular}{|c|c|c|c|}
\hline $\begin{array}{c}\text { Drug Likeness } \\
\text { Properties }\end{array}$ & Curcumin I & Curcumin II & Curcumin III \\
\hline Molecular Weight & $368.38 \mathrm{~g} / \mathrm{mol}$ & $338.35 \mathrm{~g} / \mathrm{mol}$ & $308.33 \mathrm{~g} / \mathrm{mol}$ \\
\hline LogP & 3.27 & 2.78 & 1.75 \\
\hline LogS & -3.94 & -3.92 & -3.80 \\
\hline H-bond Acceptor & 6 & 5 & 2 \\
\hline H-bond Donor & 2 & 2 & 89.82 \\
\hline Molar Refractivity & 102.80 & 96.31 & 23 \\
\hline Heavy Atoms & 27 & 12 & $74.60 \AA^{2}$ \\
\hline TPSA & $93.06 \AA^{2}$ & $83.83 \AA^{2}$ & 6 \\
\hline Rotatable bonds & 8 & 8 & -4.48 \\
\hline Drug Likeness Score & -2.63 & -3.55 & 0.41 \\
\hline Drug Score & 0.53 & 0.41 & \\
\hline
\end{tabular}

Table 2: Result of drug likeness property analysis of Curcumin I (PubChem CID: 969516), Curcumin II (PubChem CID: 5469424) and Curcumin III (PubChem CID: 5315472). Lipinski's rule of five: Molecular weight: $<500$, Number of H-bond donors: $\leq 5$; Number of H-bond acceptors: $\leq 10$; Lipophilicity (expressed as LogP): $<5$; and Molar refractivity: 40-130. 


\subsection{ADME/T Test}

Results of ADME/T test are summarized in Table 3. All the selected ligand molecules showed blood brain barrier and Caco2 cell membrane permeability. All of them showed positive indication of human intestinal absorption. Curcumin I and II are substrates of cell membrane Pglycoprotein whereas Curcumin III is a non-substrate. All of them are non-substrate for CYP450 3A4, CYP450 2C9 and CYP450 2D6 metabolic enzymes. Curcumin II and III are non-inhibitors of CYP450 2D6 whereas Curcumin I is an inhibitor. All of the selected ligand molecules are inhibitors of CYP450 1A2, CYP450 2C9 and CYP450 2C19 metabolic enzymes. All of the selected ligand molecules exhibited high CYP450 inhibitory promiscuity, no AMES toxicity and non-carcinogenicity. All of them are not readily biodegradable and showed type III acute oral toxicity. 


\begin{tabular}{|c|c|c|c|}
\hline Properties & Curcumin I & Curcumin II & Curcumin III \\
\hline Blood-Brain Barrier & $\mathrm{BBB}+$ & $\mathrm{BBB}+$ & $\mathrm{BBB}+$ \\
\hline $\begin{array}{l}\text { Human Intestinal } \\
\text { Absorption }\end{array}$ & $\mathrm{HIA}+$ & $\mathrm{HIA}+$ & $\mathrm{HIA}+$ \\
\hline Caco-2 Permeability & $\mathrm{Caco} 2+$ & $\mathrm{Caco} 2+$ & Caco2+ \\
\hline P-glycoprotein Substrate & Substrate & Substrate & Non-substrate \\
\hline CYP450 2C9 Substrate & Non-substrate & Non-substrate & Non-substrate \\
\hline CYP450 2D6 Substrate & Non-substrate & Non-substrate & Non-substrate \\
\hline CYP450 3A4 Substrate & Non-substrate & Non-substrate & Non-substrate \\
\hline CYP450 1A2 Inhibitor & Inhibitor & Inhibitor & Inhibitor \\
\hline CYP450 2C9 Inhibitor & Inhibitor & Inhibitor & Inhibitor \\
\hline CYP450 2D6 Inhibitor & Inhibitor & Non-inhibitor & Non-inhibitor \\
\hline CYP450 2C19 Inhibitor & Inhibitor & Inhibitor & Inhibitor \\
\hline CYP450 3A4 Inhibitor & Non-inhibitor & Non-inhibitor & Inhibitor \\
\hline $\begin{array}{l}\text { CYP Inhibitory } \\
\text { Promiscuity }\end{array}$ & $\begin{array}{l}\text { High CYP Inhibitory } \\
\text { Promiscuity }\end{array}$ & $\begin{array}{l}\text { High CYP Inhibitory } \\
\text { Promiscuity }\end{array}$ & $\begin{array}{c}\text { Low CYP Inhibitory } \\
\text { Promiscuity }\end{array}$ \\
\hline AMES Toxicity & Non AMES toxic & Non AMES toxic & Non AMES toxic \\
\hline Carcinogens & Non-carcinogens & Non-carcinogens & Non-carcinogens \\
\hline Biodegradation & Not ready biodegradable & Not ready biodegradable & Not ready biodegradable \\
\hline Acute Oral Toxicity & III & III & III \\
\hline
\end{tabular}

Table 3: ADME/T properties of Curcumin I (PubChem CID: 969516), Curcumin II (PubChem CID: 5469424) and Curcumin III (PubChem CID: 5315472). BBB+: Capable of penetrating blood brain barrier (BBB); HIA+: Absorbed in human intestinal tissue; Caco-2+: Permeable through the membrane of Caco-2 cell lines; CYP450: Cytochrome P450. 


\subsection{Pharmacological Activity Prediction}

The results of pharmacological activity prediction are summarized in Table 4. Curcumin I, II and

III were analyzed for 25 intended biological activities. All selected ligand molecules showed almost similar pharmacological activities although their scores varied slightly with respect to specific activity. Curcumin II showed 13 pharmacological activities with a Pa score greater than 0.7 whereas Curcumin I and III showed 12 pharmacological activities each with a Pa score greater than 0.7 .

\begin{tabular}{|c|c|c|c|c|c|c|c|}
\hline \multirow{2}{*}{$\begin{array}{l}\text { Sl. } \\
\text { No. }\end{array}$} & \multirow{2}{*}{$\begin{array}{c}\text { Biological } \\
\text { Activity }\end{array}$} & \multicolumn{2}{|c|}{ Curcumin I } & \multicolumn{2}{|c|}{ Curcumin II } & \multicolumn{2}{|c|}{ Curcumin III } \\
\hline & & $\mathbf{P a}$ & $\mathbf{P i}$ & $\mathbf{P a}$ & $\mathbf{P i}$ & $\mathbf{P a}$ & $\mathbf{P i}$ \\
\hline 01. & Antiallergic & 0.435 & 0.043 & 0.408 & 0.050 & 0.251 & 0.129 \\
\hline 02. & Antiinflammatory & 0.677 & 0.019 & 0.667 & 0.020 & 0.704 & 0.015 \\
\hline 03. & Antimutagenic & 0.814 & 0.004 & 0.834 & 0.003 & 0.790 & 0.004 \\
\hline 04. & Apoptosis agonist & 0.803 & 0.008 & 0.861 & 0.005 & 0.871 & 0.005 \\
\hline 05 & Antiulcerative & 0.651 & 0.007 & 0.650 & 0.007 & 0.633 & 0.009 \\
\hline 06. & Antioxidant & 0.610 & 0.004 & 0.624 & 0.004 & 0.637 & 0.004 \\
\hline 07. & Caspase 3 stimulant & 0.747 & 0.009 & 0.719 & 0.010 & 0.492 & 0.029 \\
\hline 08. & Chemopreventive & 0.692 & 0.007 & 0.718 & 0.006 & 0.576 & 0.011 \\
\hline 09. & Carminative & 0.833 & 0.003 & 0.810 & 0.004 & 0.822 & 0.003 \\
\hline 10. & DNA ligase (ATP) inhibitor & 0.314 & 0.040 & 0.326 & 0.036 & 0.364 & 0.024 \\
\hline 11. & Free radical scavenger & 0.766 & 0.003 & 0.785 & 0.003 & 0.670 & 0.004 \\
\hline 12. & Fibrinolytic & 0.731 & 0.013 & 0.735 & 0.012 & 0.717 & 0.017 \\
\hline 13. & $\begin{array}{c}\text { Gluconate 2-dehydrogenase } \\
\text { inhibitor }\end{array}$ & 0.833 & 0.010 & 0.822 & 0.012 & 0.836 & 0.009 \\
\hline 14. & Hepatoprotectant & 0.469 & 0.023 & 0.656 & 0.009 & 0.578 & 0.014 \\
\hline 15. & HMOX1 expression enhancer & 0.826 & 0.003 & 0.854 & 0.003 & 0.858 & 0.003 \\
\hline 16. & $\begin{array}{c}\text { Membrane permeability } \\
\text { inhibitor }\end{array}$ & 0.724 & 0.029 & 0.736 & 0.025 & 0.721 & 0.030 \\
\hline 17. & Prostate cancer treatment & 0.554 & 0.006 & 0.555 & 0.006 & 0.573 & 0.005 \\
\hline 18. & Proliferative diseases treatment & 0.558 & 0.014 & 0.590 & 0.011 & 0.553 & 0.014 \\
\hline 19. & Reductant & 0.864 & 0.003 & 0.884 & 0.003 & 0.908 & 0.003 \\
\hline 20. & Radioprotector & 0.559 & 0.019 & 0.561 & 0.019 & 0.566 & 0.019 \\
\hline 21. & Sigma receptor agonist & 0.505 & 0.024 & 0.521 & 0.022 & 0.488 & 0.027 \\
\hline 22. & Sugar-phosphatase inhibitor & 0.593 & 0.057 & 0.555 & 0.067 & 0.782 & 0.019 \\
\hline 23. & TNF expression inhibitor & 0.764 & 0.004 & 0.901 & 0.002 & 0.825 & 0.003 \\
\hline 24. & $\begin{array}{l}\text { UDP-glucuronosyltransferase } \\
\text { substrate }\end{array}$ & 0.747 & 0.011 & 0.775 & 0.009 & 0.739 & 0.012 \\
\hline 25. & Vasoprotector & 0.678 & 0.012 & 0.620 & 0.017 & 0.654 & 0.014 \\
\hline
\end{tabular}

Table 4: Pharmacological activities of Curcumin I (PubChem CID: 969516), Curcumin II (PubChem CID: 5469424) and Curcumin III (PubChem CID: 5315472). When Pa>0.7: Compound is very likely to exhibit the activity; When $0.7>\mathrm{Pa}>0.5$ : Compound is likely to exhibit the activity; When $\mathrm{Pa}<0.5$ :

Compound is less likely to exhibit the activity. 


\subsection{P450 Site of Metabolism Prediction}

The result of P450 metabolism prediction is summarized in Table 5 and depicted using Figure.

Carbon13 and Carbon1 were the most prominent atoms in Curcumin I and II which exhibited lowest enzyme scores for metabolism by 3 isoforms (3A4, 2D6 and 2C9) of CYP450 family of enzymes. And in case of Curcumin III, Carbon11 showed the lowermost enzyme scores for all the isoforms of metabolic enzymes. However, Carbon2, Carbon6, Carbon22, Carbon23 and Carbon26also showed satisfactory enzyme score indicating the probability of being catalyzed by all three enzymes.

\begin{tabular}{|c|c|c|c|c|c|c|}
\hline Compounds & Enzymes & Ranking & Atom & Enzyme Score & Energy & 2DSASA \\
\hline \multirow{9}{*}{ Curcumin I } & \multirow{3}{*}{ CYP3A4 } & 1. & C.13 & 43.6 & 48.5 & 22.4 \\
\hline & & 2. & C.26 & 51.6 & 62.2 & 64.3 \\
\hline & & 3. & C.23 & 66.5 & 74.1 & 27.8 \\
\hline & \multirow{3}{*}{ CYP2D6 } & 1. & C.1 & 59.6 & 62.2 & 64.3 \\
\hline & & 2. & C.13 & 74.5 & 48.5 & 22.4 \\
\hline & & 3. & C. 22 & 89.5 & 77.2 & 28.6 \\
\hline & \multirow{3}{*}{ CYP2C9 } & 1. & C.1 & 59.6 & 62.2 & 64.3 \\
\hline & & 2. & C.13 & 71.3 & 48.5 & 22.4 \\
\hline & & 3. & C. 22 & 87.9 & 77.2 & 28.6 \\
\hline \multirow{9}{*}{ Curcumin II } & \multirow{3}{*}{ CYP3A4 } & 1. & C.13 & 43.6 & 48.5 & 22.4 \\
\hline & & 2. & C.1 & 51.6 & 62.2 & 64.3 \\
\hline & & 3. & C.6 & 66.5 & 74.1 & 27.8 \\
\hline & \multirow{3}{*}{ CYP2D6 } & 1. & C.1 & 59.6 & 62.2 & 64.3 \\
\hline & & 2. & C.13 & 74.5 & 48.5 & 22.4 \\
\hline & & 3. & C. 22 & 89.3 & 77.2 & 31.3 \\
\hline & \multirow{3}{*}{ CYP2C9 } & 1. & C.1 & 59.6 & 62.2 & 64.3 \\
\hline & & 2. & C.13 & 71.3 & 48.5 & 22.4 \\
\hline & & 3. & C. 22 & 87.7 & 77.2 & 31.3 \\
\hline \multirow{9}{*}{ Curcumin III } & \multirow{3}{*}{ CYP3A4 } & 1. & C.11 & 43.6 & 48.5 & 22.4 \\
\hline & & 2. & C.2 & 68.9 & 77.2 & 31.3 \\
\hline & & 3. & C.1 & 73.2 & 80.8 & 28.6 \\
\hline & \multirow{3}{*}{ CYP2D6 } & 1. & C.11 & 74.5 & 48.5 & 22.4 \\
\hline & & 2. & C.2 & 89.3 & 77.2 & 31.3 \\
\hline & & 3. & C.1 & 99.8 & 80.8 & \\
\hline & \multirow{3}{*}{ CYP2C9 } & 1. & C.11 & 71.3 & 48.5 & 22.4 \\
\hline & & 2. & C. 2 & 87.7 & 77.2 & 31.3 \\
\hline & & 3. & C.1 & 97.4 & 80.8 & 28.6 \\
\hline
\end{tabular}

Table 5: Result of P450 metabolism site prediction. Atoms are ranked on the basis of lowest enzyme score which means highest probability of being catalyzed by enzyme. Enzyme Score: Energy - 8*A-0.04*SASA. A: Accessibility (not shown) is the relative distance of atom from centre of molecule. Energy: approximate activation energy required for CYP active site to catalyze particular atom. SASA: Solvent Accessible Surface Area means local accessibility of atom. 2DSASA: value calculated from molecular topology. 
(1)
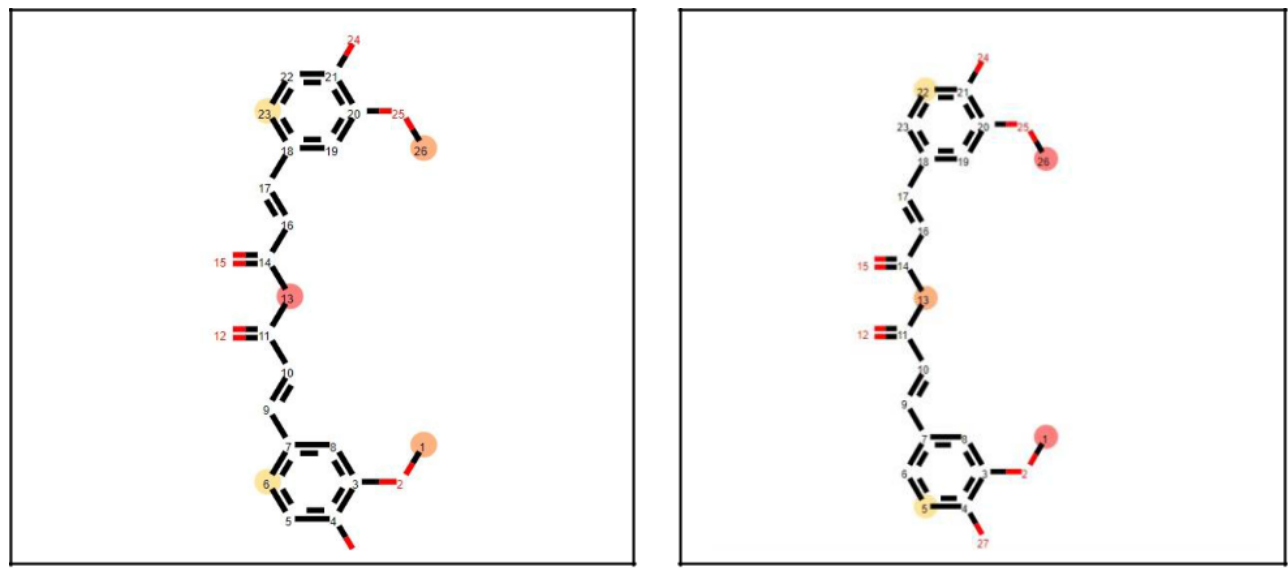

(2)
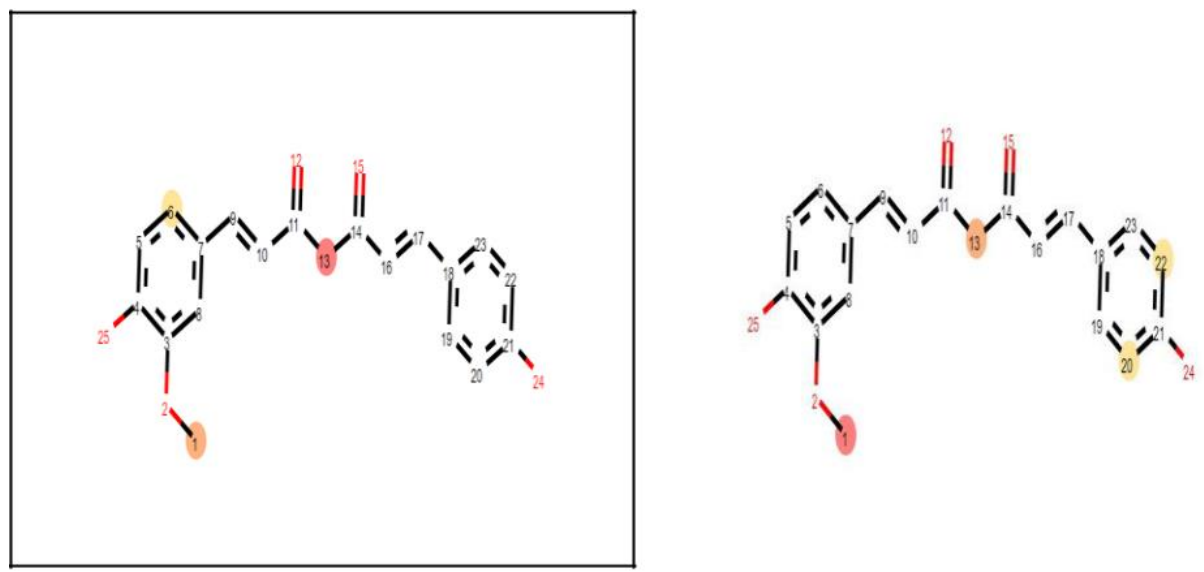

(3)

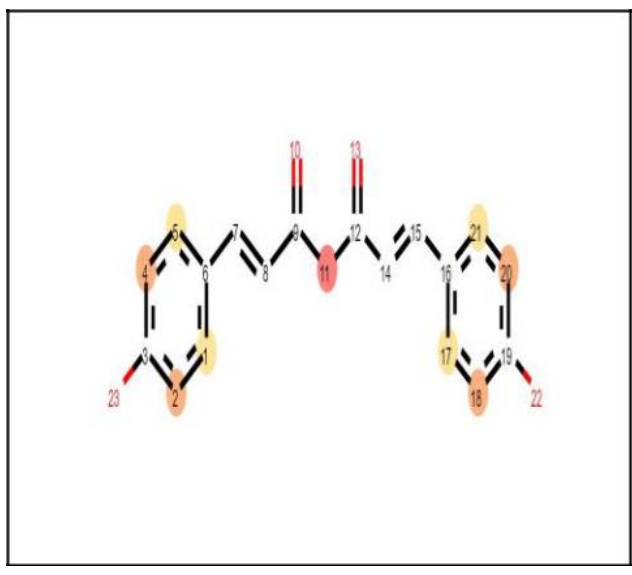

(A)

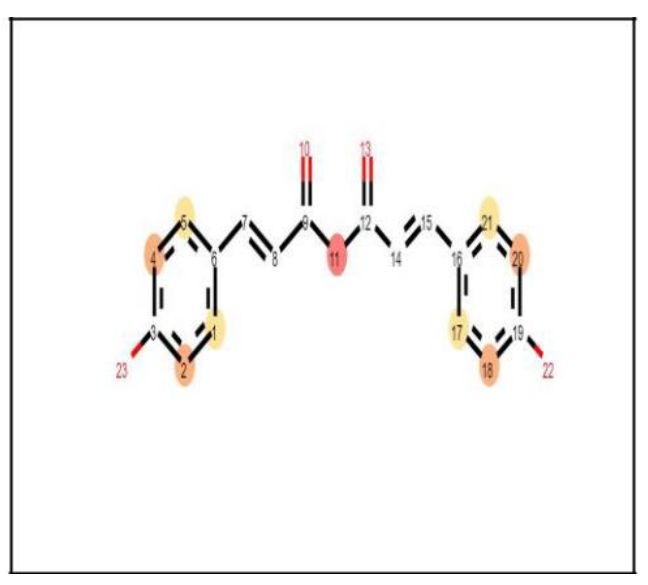

(B)
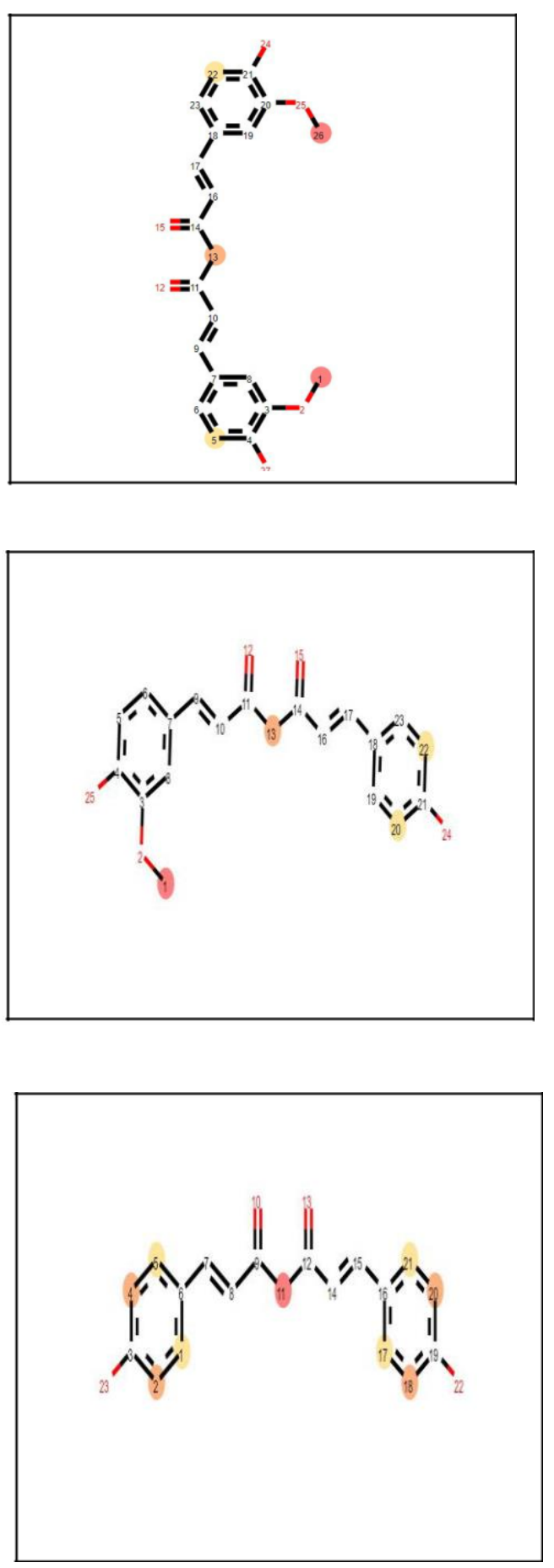

(C)

Figure 7: Representation of best possible atoms (marked in colored spheres) of (1) Curcumin I (PubChem CID: 969516), (2) Curcumin II (PubChem CID: 5469424) and (3) Curcumin III (PubChem CID: 5315472) subjected to metabolism by CYP450 group of enzymes (A) CYP 3A4, (B) CYP 2D6 and (C) CYP 2C9. Atoms marked in darker sphere are subjected to have better probability of metabolism by enzymes followed by ones marked in lighter sphere. 


\section{Discussion}

Medicinal plants are the source of novel phytocompounds which provide numerous therapeutic benefits. Many plant derived compounds and plant extract have been shown to have wound healing activity [39]. Curcuma longa has already been reported in the laboratory experiment to exhibit wound healing activity [40] [41]. The involvement of Wnt signaling and upregulation of this signaling pathway in cutaneous wound healing and injury repair process have been demonstrated in laboratory experiment [42][43]. In this study Curcuminoids (Figure 3) (Curcumin I, II and III) from Curcuma longa were docked against 2 components (Figure 4) (Casein Kinase 1 and Glycogen Synthase Kinase 3 Beta) of Wnt/ $\beta$-catenin signaling pathway based on the hypothesis that the ligand molecules bind to the target and might augment their activity.

Molecular docking is a method of estimating preferred orientation of small molecule when bound to the binding site of a second molecule. It is one of the most frequently used techniques in structure-based drug designing [44]. Molecular docking works on specific scoring algorithm and assigns binding energy to the ligand molecules that fit with the target which reflects the binding affinity. The low binding energy of a ligand molecule with target indicates high stability of the ligand-receptor complex meaning they remain more time in contact [45]. In this experiment Curcumin I interacted with CK1 with lowest binding energy $(-10.311 \mathrm{Kcal} / \mathrm{mol})$ and Curcumin II interacted with GSK3B with lowest binding energy $(-7.588 \mathrm{Kcal} / \mathrm{mol})$ suggesting the most favorable binding (Table 1). As a consequence Curcumin I interacted with highest number of amino acid residues (10) in the binding site backbone of CK1 and Curcumin II 
interacted with 8 amino acid residues within the binding site of GSK3B (Figure 5 and 6). Curcumin I also showed almost similar binding energy $(-7.533 \mathrm{Kcal} / \mathrm{mol})$ as with Curcumin II for interaction with GSK3B. However, Curcumin III showed highest binding energies for both CK1 and GSK3B binding sites. Hydrogen bonding and hydrophobic interactions play key role by strengthening the drug-receptor interaction. All of the selected ligand molecules formed significant number of hydrogen bonds and hydrophobic interactions within the binding site of the target molecules [46].

Drug likeness property evaluation is an important determinant of the successful drug discovery approach. It helps in specifying physicochemical properties of ligand molecules and helps in determining whether a drug should pass the Phase I clinical trial or not. In this experiment ligand molecules were examined according to Lipinski's rule of five which states that drugs are likely to have poor bioavailability and lower permeation which violates the rules [38] [47]. All of the selected ligand molecules followed Lipinski's rule of five. Moreover, 10 or fewer rotatable bonds and topological polar surface area equal (TPSA) to or less than $140 \AA^{2}$ are considered to contribute for better oral bioavailability of the candidate drug molecule [48]. All of the selected ligand molecules have TPSA lower than $140 \AA^{2}$ and rotatable bonds lower than 10 . Higher molecular weight reduces the permeability of drug through lipid bilayer and lower ones help in the increment of drug permeability. $\log \mathrm{P}$ is expressed in the context of lipophilicity and referred as the logarithm of partition coefficient of the candidate molecule in organic and aqueous phase. Lipophilicity affects the absorption of the candidate drug molecule inside the human body. Higher $\log \mathrm{P}$ is associated with lower absorption of the drug inside human body and lower value ensures higher rate of absorption of the candidate drug molecule. LogS value influences the solubility of the candidate molecule and the lowest value is always preferred for the drug 
molecule under investigation in a drug discovery approach. The number of hydrogen bond donors and acceptors outside the acceptable range again influences the ability of a drug molecule to cross bilayer membrane of cell. All of the selected ligand molecules followed Lipinski's rule of five in this experiment [49] [50]. All selected molecules showed druggable properties within acceptable range (Table 2 ).

Application of in silico ADME/T test has gained attention of researchers over the last decade. In silico investigation of adsorption, distribution, metabolism and toxicity has enhanced the in-vitro $\mathrm{ADME} / \mathrm{T}$ test and thus has reduced the time and cost along with increasing the success rate of drug discovery approach [51-58]. Blood brain barrier permeability becomes major concern when drugs target primarily the cells of central nervous system (CNS). Oral delivery system is the most commonly used route of drug administration and the administered drug passes through the digestive tract so it is appreciable that the drug is highly absorbed in human intestinal tissue. Pglycoproteins are embedded on the cell membrane facilitate the transport of many drugs inside the cell and therefore its inhibition may affect the normal drug transport. In vitro study of drug permeability test utilizes Caco 2 cell line and its permeability to the intended candidate drug molecule reflects that the drug is easily absorbed in the intestine [59]-[61]. All Curcumin analogues were reported to be non-inhibitory to P-glycoprotein, permeable through blood brain barrier, absorbable in the human intestinal tissue and permeable through membrane Caco2 cell lines. Cytochrome P450 family of enzymes plays major role in drug interaction, metabolism and excretion inside the body. Inhibition of these enzymes may lead to the elevation of drug toxicity, slow clearance and malfunction of the drug compound [62]. Inhibitory effect of all three Curcumin analogues was observed against multiple enzymes which may lead to poor degradability and slow excretion of those compounds inside human body. The acute oral toxicity 
is expressed in terms of median lethal dose (LD50), the dose that is capable of killing $50 \%$ of the animals under study within 24 hours. Chemicals can be classified into 4 categories (I to IV) based on their extent to induce oral toxicity [63][64]. All selected ligand molecules showed type III oral toxicity. Mutagenicity is considered as one of the most common end point of toxicity. AMES toxicity examines the toxicity of chemicals [65][66]. None of the selected ligand molecules showed AMES toxicity and carcinogenicity (Table 3).

Prediction of Activity Spectra for Substances (PASS) predicts the biological activity spectrum of a compound based on its native structure. PASS predicts the activity of a compound based on Structure Activity Relationship Base (SAR Base) which assumes that the activity of a compound is related to its structure. It functions by comparing the $2 \mathrm{D}$ structure of a compound relative to another well known compound having biological activities existing in the database with almost 95\% accuracy [67]. It predicts the result in the context of probability of activity (Pa) and Probability of inactivity (Pi) of a compound and the result varies between 0.000 and 1.000. When $\mathrm{Pa}>\mathrm{Pi}$ only then the activity is considered possible for a compound [68]. When $\mathrm{Pa}>0.7$, then the compound is very likely to exhibit the activity but possibility of the compound being analogue to a known pharmaceutical is also high. When $0.5<\mathrm{Pa}<0.7$, then the compound is likely to exhibit the activity but the probability is less along with the chance of being a known pharmaceutical agent is also lower. When $\mathrm{Pa}<0.5$, then the compound is less likely to exhibit the activity [69]. Curcumin II was reported to be more biologically active than other two compounds for 25 selected activities (Table 4).

Cytochrome P450 (CYP450) family comprises 57 isoforms of enzymes responsible for xenobiotic metabolism inside human body. So, rigorous testing of compound's probability of being metabolized by the CYP450 enzymes is a prerequisite for drug discovery approach. In 
silico approach for CYP450 utilizes 2D structure of a compound to determine which site in a molecule is more liable to metabolism by CYP450 enzymes [70] [71]. Curcumin I showed better result in P450 site of metabolism prediction (Table 5) (Figure 7).

All the selected ligand molecules docked successfully with both targets and therefore all of them might have roles in wound healing. However, Curcumin I showed highest affinity of binding ($10.311 \mathrm{Kcal} / \mathrm{mol})$ with $\mathrm{CK} 1$ and Curcumin II showed highest affinity of binding (-7.588 $\mathrm{Kcal} / \mathrm{mol}$ ) with GSK3B which may indicate their better potentiality to play significant role in wound healing. All of the selected ligand molecules performed well in drug likeness property analysis test and ADME/T test but their possibility of metabolism by CYP450 enzymes was poor which may make their chance questionable to consider as a drug. However, further investigation and intervention might be required to improve their metabolism and excretion profile inside human body. All Curcumin analogues showed some significant biological activities in PASS prediction test which should strengthen their possibility to be considered as drug.

Considering all the parameters of the tests in this experiment it can be concluded that, Curcumin I is the best enhancer of $\mathrm{CK} 1$ in and Curcumin II is the best enhancer of GSK3B in Wnt signaling pathway. However, other compounds should also be investigated further since they also performed well in docking experiment. Further in vitro and in vivo studies are required to confirm the roles of Curcumin analogues in wound healing.

\section{Conclusion}

Three Curcumins from Curcuma longa were utilized in this experiment in a search for a drug to be used in wound healing and injury repair process. Several tests indicated positive result suggesting that Curcuma longa could be a great source of herbal drug for wound healing and 
injury repair along with some other diseases as predicted in PASS. Hopefully, this study will raise research interest among researchers.

\section{Acknowledgements}

Authors are thankful to Swift Integrity Computational Lab, Dhaka, Bangladesh, a virtual platform of young researchers for providing the tools.

\section{Conflict of Interest}

The authors declare that there is no conflict of interest regarding the publication of this paper.

\section{References}

1. Bowler, P.G., Duerden, B.I. and Armstrong, D.G., 2001. Wound microbiology and associated approaches to wound management. Clinical microbiology reviews, 14(2), pp.244-269.

2. Westgate, S.J., Percival, S.L., Knottenbelt, D.C., Clegg, P.D. and Cochrane, C.A., 2011. Microbiology of equine wounds and evidence of bacterial biofilms. Veterinary microbiology, 150(1-2), pp.152-159.

3. Whyte, J.L., Smith, A.A. and Helms, J.A., 2012. Wnt signaling and injury repair. Cold Spring Harbor perspectives in biology, 4(8), p.a008078.

4. Fathke, C., Wilson, L., Shah, K., Kim, B., Hocking, A., Moon, R. and Isik, F., 2006. Wnt signaling induces epithelial differentiation during cutaneous wound healing. BMC cell biology, 7(1), p.4. 
5. Cheon, S.S., Nadesan, P., Poon, R. and Alman, B.A., 2004. Growth factors regulate $\beta$ catenin-mediated TCF-dependent transcriptional activation in fibroblasts during the proliferative phase of wound healing. Experimental cell research, 293(2), pp.267-274.

6. Zamierowski, D.S., Zamierowski David S, 1990. Wound dressing and treatment method. U.S. Patent 4,969,880.

7. Pu, L. (2015). Aesthetic plastic surgery in Asians. New York: Thieme Medical.

8. Daryabeigi, R., Heidari, M., Hosseini, S.A. and Omranifar, M., 2010. Comparison of healing time of the 2nd degree burn wounds with two dressing methods of fundermol herbal ointment and 1\% silver sulfadiazine cream. Iranian journal of nursing and midwifery research, 15(3), p.97.

9. Budovsky, A., Yarmolinsky, L. and Ben-Shabat, S., 2015. Effect of medicinal plants on wound healing. Wound Repair and Regeneration, 23(2), pp.171-183.

10. Chattopadhyay, I., Biswas, K., Bandyopadhyay, U. and Banerjee, R.K., 2004. Turmeric and curcumin: Biological actions and medicinal applications. CURRENT SCIENCE-BANGALORE, 87, pp.44-53.

11. Jayaprakasha, G.K., Jagan Mohan Rao, L. and Sakariah, K.K., 2002. Improved HPLC method for the determination of curcumin, demethoxycurcumin, and bisdemethoxycurcumin. Journal of agricultural and food chemistry, 50(13), pp.3668-3672.

12. Demirovic, D. and Rattan, S.I., 2011. Curcumin induces stress response and hormetically modulates wound healing ability of human skin fibroblasts undergoing ageing in vitro. Biogerontology, 12(5), pp.437-444. 
13. Xiong, Y., Zhou, L., Su, Z., Song, J., Sun, Q., Liu, S.S., Xia, Y., Wang, Z. and Lu, D., 2019.

longdaysin inhibits Wnt/ $\beta$-catenin signaling and exhibits antitumor activity against breast cancer. OncoTargets and therapy, 12, p.993.

14. Huang, $H$. and He, X., 2008. Wnt/ $\beta$-catenin signaling: new (and old) players and new insights. Current opinion in cell biology, 20(2), pp.119-125.

15. Cruciat, C.M., 2014. Casein kinase 1 and Wnt/ $\beta$-catenin signaling. Current opinion in cell biology, 31, pp.46-55.

16. Polakis, P., 2000. Wnt signaling and cancer. Genes \& development, 14(15), pp.1837-1851.

17. Suomalainen, M. and Thesleff, I., 2010. Patterns of Wnt pathway activity in the mouse incisor indicate absence of Wnt/ $\beta$-catenin signaling in the epithelial stem cells. Developmental dynamics: an official publication of the American Association of Anatomists, 239(1), pp.364-372.

18. Mao, J., Wang, J., Liu, B., Pan, W., Farr III, G.H., Flynn, C., Yuan, H., Takada, S., Kimelman, D., Li, L. and Wu, D., 2001. Low-density lipoprotein receptor-related protein-5 binds to Axin and regulates the canonical Wnt signaling pathway. Molecular cell, 7(4), pp.801-809.

19. MacDonald, B.T., Semenov, M.V. and He, X., 2007. SnapShot: Wnt/ $\beta$-catenin signaling. Cell, 131(6), pp.1204-e1.

20. Silkstone, D., Hong, H. and Alman, B.A., 2008. $\beta$-Catenin in the race to fracture repair: in it to Wnt. Nature Reviews Rheumatology, 4(8), p.413. 
21. Zhang, H., Nie, X., Shi, X., Zhao, J., Chen, Y., Yao, Q., Sun, C. and Yang, J., 2018. Regulatory Mechanisms of the Wnt/ $\beta$-catenin Pathway in Diabetic cutaneous Ulcers. Frontiers in pharmacology, 9 .

22. Nusse, R., 2005. Wnt signaling in disease and in development. Cell research, 15(1), p.28.

23. MacDonald, B.T., Tamai, K. and He, X., 2009. Wnt/ $\beta$-catenin signaling: components, mechanisms, and diseases. Developmental cell, 17(1), pp.9-26.

24. Kneidinger, N., Yildirim, A.O., Callegari, J., Takenaka, S., Stein, M.M., Dumitrascu, R., Bohla, A., Bracke, K.R., Morty, R.E., Brusselle, G.G. and Schermuly, R.T., 2011. Activation of the $\mathrm{WNT} / \beta$-catenin pathway attenuates experimental emphysema. American journal of respiratory and critical care medicine, 183(6), pp.723-733.

25. Baron, R. and Rawadi, G., 2007. Targeting the Wnt/ $\beta$-catenin pathway to regulate bone formation in the adult skeleton. Endocrinology, 148(6), pp.2635-2643.

26. Bafico, A., Gazit, A., Pramila, T., Finch, P.W., Yaniv, A. and Aaronson, S.A., 1999. Interaction of frizzled related protein (FRP) with Wnt ligands and the frizzled receptor suggests alternative mechanisms for FRP inhibition of Wnt signaling. Journal of Biological Chemistry, 274(23), pp.16180-16187.

27. Clevers, H., 2006. Wnt/ $\beta$-catenin signaling in development and disease. Cell, 127(3), pp.469480.

28. Akhmetshina, A., Palumbo, K., Dees, C., Bergmann, C., Venalis, P., Zerr, P., Horn, A., Kireva, T., Beyer, C., Zwerina, J. and Schneider, H., 2012. Activation of canonical Wnt signalling is required for TGF- $\beta$-mediated fibrosis. Nature communications, 3, p.735. 
29. Schrödinger Release 2018-4: Protein Preparation Wizard; Epik, Schrödinger, LLC, New York, NY, 2016; Impact, Schrödinger, LLC, New York, NY, 2016; Prime, Schrödinger, LLC, New York, NY, 2018.

30. Schrödinger Release 2018-4: LigPrep, Schrödinger, LLC, New York, NY, 2018.

31. Schrödinger Release 2019-3: Glide, Schrödinger, LLC, New York, NY, 2019.

32. Dassault Systèmes BIOVIA, Discovery Studio Visualizer, 19.1, San Diego: Dassault Systèmes, 2019.

33. Daina, A., Michielin, O. and Zoete, V., 2017. SwissADME: a free web tool to evaluate pharmacokinetics, drug-likeness and medicinal chemistry friendliness of small molecules. Scientific reports, 7, p.42717.

34. Sander, T., 2001. OSIRIS property explorer. Organic Chemistry Portal.

35. Cheng, F., Li, W., Zhou, Y., Shen, J., Wu, Z., Liu, G., Lee, P.W. and Tang, Y., 2012. admetSAR: a comprehensive source and free tool for assessment of chemical ADMET properties.

36. Rydberg, P., Gloriam, D.E. and Olsen, L., 2010. The SMARTCyp cytochrome P450 metabolism prediction server. Bioinformatics, 26(23), pp.2988-2989.

37. Filimonov D.A., Lagunin A.A., Gloriozova T.A., Rudik A.V., Druzhilovskii D.S., Pogodin P.V., Poroikov V.V. (2014). Prediction of the biological activity spectra of organic compounds using the PASS online web resource. Chemistry of Heterocyclic Compounds, 50 (3), 444-457. 
38. Lipinski CA, Lombardo F, Dominy BW, Feeney PJ. Experimental and computational approaches to estimate solubility and permeability in drug discovery and development settings. Advanced drug delivery reviews. 1997 Jan 15;23(1-3):3-25.

39. Nagori, B.P. and Solanki, R., 2011. Role of medicinal plants in wound healing. Research Journal of Medicinal Plant, 5(4), pp.392-405.

40. Kundu, S., Biswas, T.K., Das, P., Kumar, S. and De, D.K., 2005. Turmeric (Curcuma longa) rhizome paste and honey show similar wound healing potential: a preclinical study in rabbits. The international journal of lower extremity wounds, 4(4), pp.205-213.

41. Fathke, C., Wilson, L., Shah, K., Kim, B., Hocking, A., Moon, R. and Isik, F., 2006. Wnt signaling induces epithelial differentiation during cutaneous wound healing. BMC cell biology, $7(1)$, p.4.

42. Purohit, S.K., Solanki, R., Mathur, V. and Mathur, M., 2013. Evaluation of wound healing activity of ethanolic extract of Curcuma longa rhizomes in male albino rats. Asian Journal of Pharmaceutical Research, 3(2), pp.79-81.

43. Fathke, C., Wilson, L., Shah, K., Kim, B., Hocking, A., Moon, R. and Isik, F., 2006. Wnt signaling induces epithelial differentiation during cutaneous wound healing. BMC cell biology, $7(1)$, p.4.

44. Gohlke, H., Hendlich, M. and Klebe, G., 2000. Knowledge-based scoring function to predict protein-ligand interactions. Journal of molecular biology, 295(2), pp.337-356.

45. Shoichet, B.K., McGovern, S.L., Wei, B. and Irwin, J.J., 2002. Lead discovery using molecular docking. Current opinion in chemical biology, 6(4), pp.439-446. 
46. Davis, A.M. and Teague, S.J., 1999. Hydrogen bonding, hydrophobic interactions, and failure of the rigid receptor hypothesis. Angewandte Chemie International Edition, 38(6), pp.736-749.

47. Kadam, R.U. and Roy, N., 2007. Recent trends in drug-likeness prediction: a comprehensive review of in silico methods. Indian Journal of Pharmaceutical Sciences, 69(5), p.609.

48. Veber, D.F., Johnson, S.R., Cheng, H.Y., Smith, B.R., Ward, K.W. and Kopple, K.D., 2002. Molecular properties that influence the oral bioavailability of drug candidates. Journal of medicinal chemistry, 45(12), pp.2615-2623.

49. Pollastri, M.P., 2010. Overview on the Rule of Five. Current protocols in pharmacology, 49(1), pp.9-12.

50. Leeson, P.D. and Springthorpe, B., 2007. The influence of drug-like concepts on decisionmaking in medicinal chemistry. Nature Reviews Drug Discovery, 6(11), p.881.

51. Yu, H. and Adedoyin, A., 2003. ADME-Tox in drug discovery: integration of experimental and computational technologies. Drug discovery today, 8(18), pp.852-861.

52. Wang, Y., Xing, J., Xu, Y., Zhou, N., Peng, J., Xiong, Z., Liu, X., Luo, X., Luo, C., Chen, K. and Zheng, M., 2015. In silico ADME/T modelling for rational drug design. Quarterly reviews of biophysics, 48(4), pp.488-515.

53. Sarkar B, Islam SS, Ullah MA, Hossain S, Prottoy MN, Araf Y, Taniya MA. Computational Assessment and Pharmacological Property Breakdown of Eight Patented and Candidate Drugs against Four Intended Targets in Alzheimer's Disease. Advances in Bioscience and Biotechnology. 2019 Nov 25;10(11):405. 
54. Ullah A, Prottoy NI, Araf Y, Hossain S, Sarkar B, Saha A. Molecular Docking and Pharmacological Property Analysis of Phytochemicals from Clitoria ternatea as Potent Inhibitors of Cell Cycle Checkpoint Proteins in the Cyclin/CDK Pathway in Cancer Cells. Computational Molecular Bioscience. 2019 Sep 6;9(03):81.

55. Prottoy NI, Sarkar B, Ullah A, Hossain S, Boby AS, Araf Y. Molecular Docking and Pharmacological Property Analysis of Antidiabetic Agents from Medicinal Plants of Bangladesh against Type II Diabetes: A Computational Approach. PharmaTutor. 2019 Sep 1;7(9):6-15.

56. Hossain S, Sarkar B, Prottoy MN, Araf Y, Taniya MA, Ullah MA. Thrombolytic Activity, Drug Likeness Property and ADME/T Analysis of Isolated Phytochemicals from Ginger (Zingiber officinale) Using In Silico Approaches. Modern Research in Inflammation. 2019 Aug 31;8(3):29-43.

57. Ullah MA, Johora FT, Sarkar B, Araf Y, Rahman MH. Curcumin analogs as the inhibitors of TLR4 pathway in inflammation and their drug like potentialities: a computer-based study. Journal of Receptors and Signal Transduction. 2020 Mar 28:1-5.

58. Sarkar B, Ullah MA, Islam SS, Rahman MH. Analysis of Plant-derived Phytochemicals as Anti-cancer Agents Targeting Cyclin Dependent Kinase-2, Human Topoisomerase IIa and Vascular Endothelial Growth Factor Receptor-2. bioRxiv. 2020 Jan 1.

59. Paul Gleeson, M., Hersey, A. and Hannongbua, S., 2011. In-silico ADME models: a general assessment of their utility in drug discovery applications. Current topics in medicinal chemistry, 11(4), pp.358-381. 
60. Li, A.P., 2001. Screening for human ADME/Tox drug properties in drug discovery. Drug discovery today, 6(7), pp.357-366.

61. Geerts, T. and Vander Heyden, Y., 2011. In silico predictions of ADME-Tox properties: drug absorption. Combinatorial chemistry \& high throughput screening, 14(5), pp.339-361.

62. Anzenbacher, P. and Anzenbacherova, E., 2001. Cytochromes P450 and metabolism of xenobiotics. Cellular and Molecular Life Sciences CMLS, 58(5-6), pp.737-747.

63. Trevan, J.W., 1927. The error of determination of toxicity. Proceedings of the Royal Society of London. Series B, Containing Papers of a Biological Character, 101(712), pp.483-514.

64. Li, X., Chen, L., Cheng, F., Wu, Z., Bian, H., Xu, C., Li, W., Liu, G., Shen, X. and Tang, Y., 2014. In silico prediction of chemical acute oral toxicity using multi-classification methods. Journal of chemical information and modeling, 54(4), pp.1061-1069.

65. Ames, B.N., Gurney, E.G., Miller, J.A. and Bartsch, H., 1972. Carcinogens as frameshift mutagens: metabolites and derivatives of 2-acetylaminofluorene and other aromatic amine carcinogens. Proceedings of the National Academy of Sciences, 69(11), pp.3128-3132.

66. Xu, C., Cheng, F., Chen, L., Du, Z., Li, W., Liu, G., Lee, P.W. and Tang, Y., 2012. In silico prediction of chemical Ames mutagenicity. Journal of chemical information and modeling, 52(11), pp.2840-2847.

67. Parasuraman, S., 2011. Prediction of activity spectra for substances. Journal of pharmacology \& pharmacotherapeutics, 2(1), p.52. 
68. Stepanchikova, A.V., Lagunin, A.A., Filimonov, D.A. and Poroikov, V.V., 2003. Prediction of biological activity spectra for substances: Evaluation on the diverse sets of drug-like structures. Current medicinal chemistry, 10(3), pp.225-233.

69. Lagunin, A., Stepanchikova, A., Filimonov, D. and Poroikov, V., 2000. PASS: prediction of activity spectra for biologically active substances. Bioinformatics, 16(8), pp.747-748.

70. https://smartcyp.sund.ku.dk/background_smartcyp

71. Tyzack, J.D. and Kirchmair, J., 2019. Computational methods and tools to predict cytochrome P450 metabolism for drug discovery. Chemical biology \& drug design, 93(4), pp.377-386. 